\title{
A Novel Analytical Model of Solute Transport in an Aquifer-Aquitard System with Mixing Processes in the Reservoirs
}

\section{Wenguang Shi}

China University of Geosciences

Wang Quanrong ( $\nabla$ wangqr@cug.edu.cn )

China University of Geosciences https://orcid.org/0000-0002-6560-6340

\section{Research Article}

Keywords: Solute transport, Vertical dispersion, Aquifer-aquitard system, Parameter estimation

Posted Date: January 6th, 2022

DOI: https://doi.org/10.21203/rs.3.rs-1019431/v1

License: (c) (i) This work is licensed under a Creative Commons Attribution 4.0 International License.

Read Full License 


\section{Title page}

2

3 A Novel Analytical Model of Solute Transport in an Aquifer-aquitard System with Mixing Processes in the Reservoirs

$6{ }^{1}$ School of Environmental Studies, China University of Geosciences, 388 Lumo Road, Wuhan

7 430074, China

$8 \quad{ }^{2}$ State Environmental Protection Key Laboratory of Source Apportionment and Control of

9 Aquatic Pollution, Ministry of Ecology and Environment, 388 Lumo Road, Wuhan 430074,

10 China

11 Corresponding author: Quanrong Wang (wangqr@cug.edu.cn)

12 Competing interests statement: Declaration of interest: "none"

13 Ethics approval and consent to participate: "Not applicable"

14 Consent for publication: "Not applicable"

15 Availability of data and materials: The datasets used and/or analyzed during the current study

16 are available from the corresponding author on reasonable request.

17 Funding: "No funds, grants, or other support was received"

18 Authors' contributions:

19 Conceptualization, Writing - review \& editing, Supervision [Quanrong Wang], Methodology,

20 Writing original draft, derivation, code, Formal analysis [Wenguang Shi] 


\section{A Novel Analytical Model of Solute Transport in an Aquifer-aquitard System with}

23 Mixing Processes in the Reservoirs

27 Wenguang Shi ${ }^{1}$ and Quanrong Wang ${ }^{1,2 *}$

$29{ }^{1}$ School of Environmental Studies, China University of Geosciences, 388 Lumo Road, Wuhan 30 430074, China

$32{ }^{2}$ State Environmental Protection Key Laboratory of Source Apportionment and Control of

33 Aquatic Pollution, Ministry of Ecology and Environment, 388 Lumo Road, Wuhan 430074,

34 China

36 Corresponding author: Quanrong Wang (wangqr@cug.edu.cn) 


\section{Highlights:}

39 1. A novel MIM analytical model of solute transport is developed in an aquifer-aquitard

$40 \quad$ system.

412 . The mixing processes in the reservoirs are important for solute transport in an aquifer-

42 aquitard system.

43 3. The performance of the new analytical model is tested by the experimental data.

44 


\section{Abstract}

46 Analytical models have been widely used to aid understanding the physical and chemical

47 processes of tracer (or chemicals) in an aquifer-aquitard system in the laboratory-controlled

48 experiment, when the observation data is few or not available during the experiment. When

49 injecting tracer into (or extracting them from) the aquifer-aquitard system during experiments,

50 the pre-inlet and after-outlet reservoirs are indispensable. However, the concentration variation

51 in the reservoirs was not treated properly in previous analytical models, resulting in poor

52 performance in interpreting experimental data. In this study, new mathematical models

53 describing the concentration variation in the pre-inlet and the after-outlet reservoirs are proposed,

54 and they are integrated into the novel analytical model. The novel analytical model is developed

55 under the mobile-immobile (MIM) framework in the aquifer-aquitard system, considering the

56 longitudinal and vertical dispersion, the advection, and the first-order chemical reaction in both

57 aquifer and aquitard. A finite-difference solution is developed and the experimental data are

58 employed to test the new analytical model. Results indicate that the concentration variation in the

59 reservoirs is important to solute transport in the aquifer-aquitard system in the laboratory-

60 controlled experiment, and the new analytical model outperforms the previous models in

61 interpreting experimental data. The global sensitivity analysis demonstrates that the output

62 concentration of solute transport in the aquifer-aquitard system is most sensitive to the volume of

63 water in the pre-inlet reservoir. The contribution of the diffusion effect to the total mass flux of

64 tracer crossing the aquifer-aquitard interface is much smaller than the contribution of the

65 dispersive and advective effects.

66 Keywords: Solute transport; Vertical dispersion; Aquifer-aquitard system; Parameter estimation 
Confidential manuscript submitted to Environmental Science and Pollution Research

\section{Introduction}

The laboratory-controlled experiment has been widely used to investigate solute transport in an aquifer-aquitard system. Due to the low permeability of fine sediments (such as clay and silt) consisting of aquitards, the groundwater release from aquitards is not easy to be observed or measured (Barbour et al., 2012; Rezanezhad et al., 2017; Rezanezhad et al., 2016; Xao et al., 2020). Alternatively, it is estimated by the mathematical models through interpreting the observed data in the adjacent aquifers (Li et al., 2021; Yang et al., 2016). Therefore, the robustness of the mathematical models is critical for understanding the mechanism of solute transport in an aquifer-aquitard system.

To date, many analytical models have been developed for solute transport in an aquiferaquitard system. As the permeability of fine sediments of the aquitard is low, the flow velocity is much smaller than that in aquifer. In the early investigations of solute transport in the aquiferaquitard system, the advective effect in the aquitard was ignored in the analytical models, such as Tang et al. (1981), Sudicky and Frind (1982), Sudicky et al. (1985), Starr et al. (1985), Chen (1985), Fujikawa and Fukui (1990), Roubinet et al. (2012), Zhou et al. (2017), Chen and Zhan (2018), Zhou and Zhan (2018), and Zhu and Zhan (2018). As the mechanical dispersion is dependent on velocity, ignoring advection implies that the dispersive effect is also ignored in the aquitard. In another word, only diffusion processes are considered in the aquitard in analytical models of the solute transport. Except Roubinet et al. (2012) and Chen and Zhan (2018), the other analytical models mentioned above assumed that the dispersion is one dimensional (1D) in the aquifer. Namely, the longitudinal dispersion is considered but the vertical dispersion is ignored in the aquifer, which means that tracer mixing processes finish instantaneously in the vertical profile of the aquifer. These models were named "averaged approximation" models 
90 (Wang and Zhan, 2013; Zhan et al., 2009a). It was found that these models performed well in

91 modeling solute transport in the fracture-matrix, as the fracture has much greater permeability

92 and smaller aperture (Chen and Zhan, 2018; Zhou and Zhan, 2018; Zhou et al., 2017). The

93 aquifer-aquitard system was different from the fracture-matrix system. This is because the

94 aquifer permeability is smaller than the fracture permeability, and the vertical thickness is greater

95 for the aquifer. As a result, the assumptions included in the "averaged approximation" models

96 might be invalid for solute transport in the aquifer-aquitard system (Wang and Zhan, 2013). Then,

97 the "averaged approximation" models have been extended by including the advective effect in

98 the aquitard, such as Tang and Aral (1992); Zhan et al. (2009a); Zhan et al. (2009b); Liu et al.

99 (2013); Rezaei et al. (2013); Wang and Zhan (2013); and Rezaei et al. (2016). Rezaei et al. (2016)

100 considered two-dimensional (2D) dispersion and 1D advection in both aquifer and aquitard.

101 However, the currently published analytical models contain an assumption that the source

102 concentration was treated as a constant (Liu et al., 2013; Rezaei et al., 2016) or a temporal-

103 dependent variable which exponentially changes with time (Fujikawa and Fukui, 1990; Starr et

104 al., 1985; Tang and Aral, 1992). Actually, such treatment could not be used to describe the

105 variation of the source concentration in the laboratory-controlled experiments. Yang et al. (2016)

106 and Li et al. (2021) conducted a two-dimensional (2D) laboratory-controlled experiment of

107 solute transport, where the schematic diagram of the aquifer-aquitard system is as shown in

108 Figure 1. There are two reservoirs connecting with aquifer, where the prepared tracer is injected

109 pre-inlet reservoir. After mixing with original water in the pre-inlet reservoir, the tracer enters

110 the aquifer-aquitard system. Therefore, the sources concentration is zero initially in the reservoir,

111 and increases with time. Probably because the analytical model considering the variable source

112 concentration in the pre-inlet reservoir is not available, Li et al. (2021) employed numerical 
113 modeling to interpret the observation data of solute transport in the aquifer-aquitard system.

114 Unfortunately, the mathematical model might be not robust, as the sources concentration

115 variation was described by the temporal-dependent exponential function, which did not fully

116 consider the mixing processes between the injected tracer and the original water in the pre-inlet

117 reservoir. Meanwhile, the numerical errors (like numerical dispersion and numerical oscillations)

118 are not be avoided completely in the numerical modeling when advection is dominant during

119 solute transport (Yeh, 2000; Zheng and Wang, 1999).

120 Another assumption involved in the current analytical models is that the outlet boundary

121 condition of the aquifer-aquitard system was not treated properly. There are two types of

122 treatments. First, the aquifer horizontal extension was assumed to be infinite(Rezaei et al., 2016;

123 Singh et al., 2020; Wang et al., 2020b). Such assumption performs well for the cases that the

124 aquifer is long enough or the experimental time is short enough that tracer could not arrive in

125 outlet boundary. Otherwise, after the tracer enters the after-outlet reservoir, as shown in Figure 1,

126 such assumption could cause errors, which had been reported in the 1D column test (Wang et al.,

127 2019). The second type of treatment is that the outlet boundary condition of solute transport was

128 described by an exponential function with time in the analytical model (Tang and Aral, 1992).

129 Such treatment is not based on physical processes of solute transport in the after-outlet reservoir.

130 Advection-dispersion equation (ADE) has been widely used to describe solute transport in

131 subsurface (Baeumer et al., 2001; Chen et al., 2018; Van Genuchten, 1985; Zhan et al., 2009a).

132 However, many recent studies demonstrated that the ADE model might not interpret the non-

133 Fickian behaviors, like early breakthrough and long tails of breakthrough curves (BTCs) (Chen

134 et al., 2017; Hansen et al., 2017; Wang et al., 2020b). Alternatively, the mobile-immobile (MIM)

135 model was used instead of the ADE model. Zhou et al. (2017) derived a new analytical model of 
136 solute transport using the MIM model. However, Zhou's model is based on the "averaged

137 approximation", which might work well for solute transport in the fracture-matrix, but not in the

138 aquifer-aquitard system.

139 In this study, the mathematical model of the concentration variation both in the pre-inlet and 140 after-outlet reservoirs will be proposed based on the mass balance and Fick's law. Such models

141 are integrated into the mathematical model of solute transport in the aquifer-aquitard system,

142 which considers longitudinal and vertical dispersion, advection, and the first-order chemical

143 reaction in both aquifer and aquitard. A novel analytical model is developed under the MIM

144 framework. The numerical modeling and the experimental data reported by Li et al. (2021) are

145 used to test the new analytical model. Global sensitivity analysis is conducted to investigate the

146 influence of input parameters on the output concentration of solute transport.

\section{2. Problem statement and mathematical model}

148 The conceptual model of this study is composed of an aquifer and an overlain aquitard with

149 uniform thickness, as shown in Figure 1. Both aquifer and aquitard are horizontal, homogeneous, 150 and isotropic. The origin of the coordinate system is located at the left-lower corner of the 151 aquifer. The $x$ - and $z$ - axes are horizontal and vertical, respectively.

Figure 1

\section{2.1. 2D models of solute transport in an aquifer-aquitard system}

154 Assuming that 1D advection, 2D dispersion, and the first-order chemical reaction are

155 involved in the solute transport processes under the MIM framework, the governing equations of

156 solute transport in the aquifer-aquitard system are 


$$
R_{\mathrm{m}} \frac{\partial C_{\mathrm{m}}}{\partial t}=D_{x} \frac{\partial^{2} C_{\mathrm{m}}}{\partial x^{2}}+D_{z} \frac{\partial^{2} C_{\mathrm{m}}}{\partial z^{2}}-v_{x} \frac{\partial C_{\mathrm{m}}}{\partial x}-\lambda_{\mathrm{m}} C_{\mathrm{m}}-\frac{\varepsilon}{\theta_{\mathrm{m}}}\left(C_{\mathrm{m}}-C_{\mathrm{im}}\right), 0 \leq z \leq b_{1}, 0 \leq x \leq L_{\mathrm{a}}
$$

$$
R_{\mathrm{um}} \frac{\partial C_{\mathrm{um}}}{\partial t}=D_{\mathrm{uz}} \frac{\partial^{2} C_{\mathrm{um}}}{\partial z^{2}}+D_{\mathrm{ux}} \frac{\partial^{2} C_{\mathrm{um}}}{\partial x^{2}}-v_{z} \frac{\partial C_{\mathrm{um}}}{\partial z}-\lambda_{\mathrm{um}} C_{\mathrm{um}}-\frac{\varepsilon_{\mathrm{u}}}{\theta_{\mathrm{um}}}\left(C_{\mathrm{um}}-C_{\mathrm{uim}}\right), b_{1} \leq z<
$$

$b_{1}+b_{2}, 0 \leq x \leq L_{\mathrm{a}}$

$$
R_{\text {uim }} \frac{\partial C_{\text {uim }}}{\partial t}=\frac{\varepsilon_{\mathrm{u}}}{\theta_{\text {uim }}}\left(C_{\text {um }}-C_{\text {uim }}\right)-\lambda_{\text {uim }} C_{\text {uim }}, b_{1} \leq z<b_{1}+b_{2}, 0 \leq x \leq L_{\mathrm{a}},
$$

163 where subscripts "m" and "im" are the parameters in the mobile and immobile domains,

164 respectively; subscripts " $u$ " is the parameters in the upper aquitard; $x$ and $z$ represent the

165 vertical and horizontal distance [L], respectively; $C_{\mathrm{m}}, C_{\mathrm{im}}, C_{\mathrm{um}}$ and $C_{\mathrm{uim}}$ are the

concentrations $\left[\mathrm{ML}^{-3}\right] ; t$ is time [T]; $b_{1}$ and $b_{2}$ are the vertical thicknesses [L] of aquifer and

167 aquitard, respectively; $L_{\mathrm{a}}$ is the horizontal length [L] of aquifer; $v_{x}$ and $v_{z}$ are the average

168 velocities $\left[\mathrm{LT}^{-1}\right]$ of the aquifer and aquitard, respectively; $v_{x}=q_{x} / \theta_{\mathrm{m}}, v_{z}=q_{z} / \theta_{\mathrm{um}}, q_{x}$ and

$169 q_{z}$ are the Darcy velocities $\left[\mathrm{LT}^{-1}\right]$ of the aquifer and aquitard, respectively; $\theta_{\mathrm{m}}, \theta_{\mathrm{im}}, \theta_{\mathrm{um}}$ and $170 \theta_{\text {uim }}$ are the porosities [dimensionless]; $\lambda_{\mathrm{m}}, \lambda_{\mathrm{im}}, \lambda_{\mathrm{um}}$ and $\lambda_{\text {uim }}$ are reaction rates $\left[\mathrm{T}^{-1}\right.$ ];

$171 R_{\mathrm{m}}=1+\frac{\rho_{\mathrm{b}} K_{\mathrm{d}}}{\theta_{\mathrm{m}}}, R_{\mathrm{im}}=1+\frac{\rho_{\mathrm{b}} K_{\mathrm{d}}}{\theta_{\mathrm{im}}}, R_{\mathrm{um}}=1+\frac{\rho_{\mathrm{b}} K_{\mathrm{d}}}{\theta_{\mathrm{um}}}$ and $R_{\mathrm{uim}}=1+\frac{\rho_{\mathrm{b}} K_{\mathrm{d}}}{\theta_{\mathrm{uim}}}$ are the retardation

172 factors [dimensionless]; $K_{\mathrm{d}}$ is the equilibrium distribution coefficient $\left[\mathrm{M}^{-1} \mathrm{~L}^{3}\right] ; \rho_{\mathrm{b}}$ is the bulk

173 density $\left[\mathrm{ML}^{-3}\right] ; \varepsilon$ and $\varepsilon_{\mathrm{u}}$ are the first-order mass transfer coefficients $\left[\mathrm{T}^{-1}\right]$ of the aquifer and 174 aquitard, respectively; $D_{x}, D_{z}, D_{\mathrm{uz}}$ and $D_{\mathrm{ux}}$ are the hydrodynamic dispersion coefficients $175\left[\mathrm{~L}^{2} \mathrm{~T}^{-1}\right]$, and one has

$$
D_{x}=\alpha_{x} v_{x}+D_{0} \text {, }
$$

$$
D_{z}=\alpha_{z} v_{x}+D_{0},
$$




$$
D_{\mathrm{uz}}=\alpha_{\mathrm{uz}} v_{z}+D_{\mathrm{u} 0}
$$

$$
D_{\mathrm{ux}}=\alpha_{\mathrm{ux}} v_{z}+D_{\mathrm{u} 0},
$$

where $\alpha_{x}, \alpha_{z}, \alpha_{\mathrm{uz}}$ and $\alpha_{\mathrm{ux}}$ refer to dispersivities [L]; $D_{0}$ and $D_{\mathrm{u} 0}$ are diffusion coefficients $\left[\mathrm{L}^{2} \mathrm{~T}^{-1}\right]$ of aquifer and aquitard, respectively. continuous, and one has

$$
\left.C_{\mathrm{m}}(x, z, t)\right|_{z=b_{1}}=\left.C_{\mathrm{um}}(x, z, t)\right|_{z=b_{1}}, 0 \leq x \leq L_{\mathrm{a}}
$$

$$
\left.\left[\theta_{\mathrm{um}} v_{z} C_{\mathrm{um}}(x, z, t)-\theta_{\mathrm{um}} D_{\mathrm{uz}} \frac{\partial C_{\mathrm{um}}(x, z, t)}{\partial z}\right]\right|_{z=b_{1}}=-\left.\theta_{\mathrm{m}} D_{z} \frac{\partial C_{\mathrm{m}}(x, z, t)}{\partial z}\right|_{z=b_{1}}, 0 \leq x \leq L_{\mathrm{a}}
$$

are

$$
\begin{aligned}
& \left.\frac{\partial C_{\mathrm{m}}(x, z, t)}{\partial z}\right|_{z=0}=0,0 \leq x \leq L_{\mathrm{a}}, \\
& \left.C_{\mathrm{um}}(x, z, t)\right|_{z=b_{1}+b_{2}}=0,0 \leq x \leq L_{\mathrm{a}}, \\
& {\left.\left[v_{x} C_{\mathrm{m}}(x, z, t)-\alpha_{x}\left|v_{x}\right| \frac{\partial C_{\mathrm{m}}(x, z, t)}{\partial x}\right]\right|_{x=0}=\left.\left[v_{x} C_{\mathrm{in}}(t)\right]\right|_{x=0}, 0 \leq z \leq b_{1},} \\
& {\left.\left[v_{x} C_{\mathrm{m}}(x, z, t)-\alpha_{x}\left|v_{x}\right| \frac{\partial C_{\mathrm{m}}(x, z, t)}{\partial x}\right]\right|_{x=L_{\mathrm{a}}}=\left.\left[v_{x} C_{\text {out }}(t)\right]\right|_{x=L_{\mathrm{a}}}, 0 \leq z \leq b_{1},}
\end{aligned}
$$

192 where $C_{\text {in }}(t)$ and $C_{\text {out }}(t)$ are the concentrations $\left[\mathrm{ML}^{-3}\right]$ in the pre-inlet and after-outlet

193 reservoirs, respectively. They could be computed by the models in Section 2.2.

194 The initial conditions used in this study are

$$
\left.C_{\mathrm{m}}(x, z, t)\right|_{t=0}=\left.C_{\mathrm{im}}(x, z, t)\right|_{t=0}=\left.C_{\mathrm{um}}(x, z, t)\right|_{t=0}=\left.C_{\mathrm{uim}}(x, z, t)\right|_{t=0}=0,0 \leq z<
$$

The new model is an extension of some previous models. For instance, when $C_{\mathrm{in}}(t)=1$, $D_{\mathrm{ux}}=0, L_{\mathrm{a}} \rightarrow \infty$, and $\varepsilon=\varepsilon_{\mathrm{u}}$, the new model reduces to the model of Zhan et al. (2009a). If $C_{\mathrm{in}}(t)=1, D_{z}=D_{\mathrm{ux}}=0, v_{z}=0$, and $L_{\mathrm{a}} \rightarrow \infty$, the new model becomes the model of Zhou et 
al. (2017). When $\varepsilon=\varepsilon_{\mathrm{u}}, C_{\mathrm{in}}(t)=C_{1}(z) \exp \left(-\zeta_{1} t\right), C_{\text {out }}(t)=C_{2}(z) \exp \left(-\zeta_{2} t\right)$, in which

$201 C_{1}(z)$ and $C_{2}(z)$ are the concentrations $\left[\mathrm{ML}^{-3}\right]$ in the inner and outer boundary conditions,

202 respectively; $\zeta_{1}$ and $\zeta_{2}$ are constants $\left[\mathrm{T}^{-1}\right]$, the new model reduces to the solution of Tang and

203 Aral (1992). If $C_{\mathrm{in}}(t)=1, D_{x}=D_{z}=D_{\mathrm{ux}}=0, v_{z}=0, L_{\mathrm{a}} \rightarrow \infty, \varepsilon=\varepsilon_{\mathrm{u}}, \lambda_{\mathrm{m}}=\lambda_{\mathrm{um}}=0$,

204 the new model becomes to the model of Zhu and Zhan (2018).

205

206

207

208

209

210

211

212

213

214

215

\subsection{Models describing concentration variation in reservoirs}

Assuming the injected tracer instantaneously and completely mixes with the original water in the pre-inlet reservoir, the concentration variation in the pre-inlet reservoir could be described as following equations based on the mass balance and the Fick's law

$$
\begin{aligned}
& V_{\text {in }} \frac{d C_{\text {in }}(t)}{d t}=-\left.Q_{\text {in }}\left[C_{\text {in }}(t)-C_{0}\right]\right|_{x=0}, 0 \leq z \leq b_{1}, \\
& \left.C_{\text {in }}(t)\right|_{t=0}=0,0 \leq z \leq b_{1},
\end{aligned}
$$

where $V_{\text {in }}$ is the volume $\left[\mathrm{L}^{3}\right]$ of water in the pre-inlet reservoir; $V_{\mathrm{in}}=L_{\mathrm{in}} w_{\mathrm{in}} h_{\mathrm{in}} ; L_{\mathrm{in}}$ and $w_{\mathrm{in}}$ are the length and width [L] of the pre-inlet reservoir, respectively; $h_{\mathrm{in}}$ is the water level in the pre-inlet reservoir; $Q_{\text {in }}$ represents the flow rate $\left[\mathrm{L}^{3} \mathrm{~T}^{-1}\right]$ entering the aquifer; $Q_{\text {in }}=b_{1} w_{\text {in }} \theta_{\mathrm{m}} v_{x}$; $C_{0}$ is concentration $\left[\mathrm{ML}^{-3}\right]$ of the prepared tracer, which is a constant. The first and second terms on the right side of Eq. (6a) represent the mass of tracer injected into the reservoir, and the mass of tracer after mixing with water term leaving the reservoir.

Similarly, the mathematical model describing the concentration variation in the after-outlet reservoir could be obtained

$$
\begin{aligned}
& V_{\text {out }} \frac{d C_{\text {out }}(t)}{d t}=\left.w_{\text {out }} b_{1} D_{x} \frac{d C_{\mathrm{m}}(x, z, t)}{d x}\right|_{x=L_{\mathrm{a}}}, 0 \leq z \leq b_{1}, \\
& \left.C_{\text {out }}(t)\right|_{t=0}=0,0 \leq z \leq b_{1}
\end{aligned}
$$


221 where $V_{\text {out }}$ is the volume $\left[\mathrm{L}^{3}\right]$ of water in the after-outlet reservoir; $V_{\text {out }}=L_{\text {out }} w_{\text {out }} h_{\text {out }} ; L_{\text {out }}$

222 and $w_{\text {out }}$ are the length and width [L] of the after-outlet reservoir, respectively; $h_{\text {out }}$ is the

223 water level in the after-outlet reservoir.

224 By checking the models of Eqs. (6) - (7), one may find that if the concentration variation in

225 the reservoirs is not measured during the experiment or the observation data is not available,

$226 C_{\text {in }}(t)$ and $C_{\text {out }}(t)$ could be computed using the parameters of injection rate, water volume of

227 the reservoirs, and the concentration of the injected tracer.

\section{3. Solutions of $2 \mathrm{D}$ solute transport in an aquifer-aquitard system}

\section{3.1. Analytical solutions in Laplace domain}

230 Eqs. (1) - (7) composed the mathematical model describing the $2 \mathrm{D}$ solute transport in an

231 aquifer-aquitard system. In this study, the Laplace transform method and the finite-cosine

232 Fourier transform method will be employed to derive the analytical model in Laplace domain.

233 The detailed derivations could be seen in Appendix A.

234 In the aquifer, the solutions in the Laplace domain are

235

236

$$
\begin{aligned}
& \bar{C}_{\mathrm{m}}=\sum_{\mathrm{n}=0}^{\infty}\left[\mathrm{N}_{\mathrm{n}} \exp \left(\alpha_{\mathrm{n}} x\right)+\mathrm{D}_{\mathrm{n}} \exp \left(\delta_{\mathrm{n}} x\right)\right] \cos \left(\omega_{\mathrm{n}} z\right), 0 \leq z \leq b_{1}, 0 \leq x \leq L_{\mathrm{a}}, \\
& \bar{C}_{\mathrm{im}}=\frac{\varepsilon / \theta_{\mathrm{im}}}{\varepsilon / \theta_{\mathrm{im}}+\lambda_{\mathrm{im}}+R_{\mathrm{im}} s} \bar{C}_{\mathrm{m}}, 0 \leq z \leq b_{1}, 0 \leq x \leq L_{\mathrm{a}},
\end{aligned}
$$

237 where the over bar refers to the terms in Laplace domain hereinafter; $s$ denotes the Laplace

238 transform parameter in respect to $t ; \omega_{\mathrm{n}}$ is the frequency terms used in the Fourier transform

239 and it could be computed by Eq. (10); $\mathrm{n}$ is a positive integer;

240

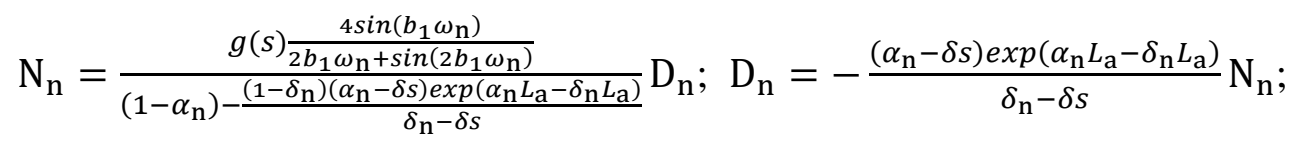


$g(s)=\frac{C_{0}}{s\left(s V_{\mathrm{in}} / Q_{\mathrm{in}}+1\right)} ; \delta=\frac{V_{\text {out }}}{w_{\text {out }} h_{\text {out }} D_{x}} ; \quad \alpha_{\mathrm{n}}=\frac{v_{x}-\sqrt{v_{x}^{2}+4 D_{x}\left(E_{1}+\omega_{\mathrm{n}}^{2}\right)}}{2 D_{x}} ; \delta_{\mathrm{n}}=\frac{v_{x}+\sqrt{v_{x}^{2}+4 D_{x}\left(E_{1}+D_{z} \omega_{\mathrm{n}}^{2}\right)}}{2 D_{x}} ;$

242

$E_{1}=\lambda_{\mathrm{m}}+R_{\mathrm{m}} s+\varepsilon / \theta_{\mathrm{m}}-\frac{\varepsilon^{2} / \theta_{\mathrm{m}} \theta_{\mathrm{im}}}{\varepsilon / \theta_{\mathrm{im}}+\lambda_{\mathrm{im}}+R_{\mathrm{im}} s}$

$$
\bar{C}_{\mathrm{um}}=\sum_{\mathrm{n}=0}^{\infty}\left[\mathrm{A}_{\mathrm{n}} \exp \left(\beta_{\mathrm{n}} z\right)+\mathrm{B}_{\mathrm{n}} \exp \left(\sigma_{\mathrm{n}} z\right)\right] \times\left[\mathrm{N}_{\mathrm{n}} \exp \left(\alpha_{\mathrm{n}} x\right)+\mathrm{D}_{\mathrm{n}} \exp \left(\delta_{\mathrm{n}} x\right)\right], b_{1} \leq z<
$$

$b_{1}+b_{2}, 0 \leq x \leq L_{\mathrm{a}}$,

$$
\bar{C}_{\mathrm{uim}}=\frac{\varepsilon_{\mathrm{u}} / \theta_{\mathrm{uim}}}{\varepsilon_{\mathrm{u}} / \theta_{\mathrm{uim}}+\lambda_{\mathrm{uim}}+R_{\mathrm{uim}} s} \bar{C}_{\mathrm{um}}, b_{1} \leq z<b_{1}+b_{2}, 0 \leq x \leq L_{\mathrm{a}}
$$

247 where $\mathrm{A}_{\mathrm{n}}=-\frac{\cos \left(\omega_{\mathrm{n}} b_{1}\right) \exp \left[\sigma_{\mathrm{n}}\left(b_{1}+b_{2}\right)-\beta_{\mathrm{n}}\left(b_{1}+b_{2}\right)\right]}{\exp \left[\sigma_{\mathrm{n}} b_{1}\right]-\exp \left[\sigma_{\mathrm{n}}\left(b_{1}+b_{2}\right)-\beta_{\mathrm{n}} b_{2}\right]} ; \mathrm{B}_{\mathrm{n}}=\frac{\cos \left(\omega_{\mathrm{n}} b_{1}\right)}{\exp \left[\sigma_{\mathrm{n}} b_{1}\right]-\exp \left[\sigma_{\mathrm{n}}\left(b_{1}+b_{2}\right)-\beta_{\mathrm{n}} b_{2}\right]} ; E_{2}=$

$\lambda_{\mathrm{um}}+s R_{\mathrm{um}}+\varepsilon_{\mathrm{u}} / \theta_{\mathrm{uim}}-\frac{\varepsilon_{\mathrm{u}}^{2} / \theta_{\mathrm{um}} \theta_{\mathrm{uim}}}{\varepsilon_{\mathrm{u}} \theta_{\mathrm{uim}}+\lambda_{\mathrm{uim}}+R_{\mathrm{uim}} s} ; \quad \beta_{\mathrm{n}}=\frac{v_{z}-\sqrt{v_{z}^{2}+4 D_{\mathrm{uz}}\left(E_{2}+D_{\mathrm{ux}} \alpha_{\mathrm{n}}^{2}\right)}}{2 D_{\mathrm{uz}}}$

$\sigma_{\mathrm{n}}=\frac{v_{z}+\sqrt{v_{\mathrm{z}}^{2}+4 D_{\mathrm{uz}}\left(E_{2}+D_{\mathrm{ux}} \alpha_{\mathrm{n}}^{2}\right)}}{2 D_{\mathrm{uz}}}$

The values of $\omega_{n}$ are the positive solution of the following function

$$
\omega_{\mathrm{n}} \tan \left(\omega_{\mathrm{n}} b_{1}\right)=\frac{W_{1}\left[v_{z} \exp \left(\beta_{\mathrm{n}} b_{1}\right)-D_{\mathrm{uz}} \beta_{\mathrm{n}} \exp \left(\beta_{\mathrm{n}} b_{1}\right)\right]}{D_{z}}+\frac{W_{2}\left[v_{z} \exp \left(\sigma_{\mathrm{n}} b_{1}\right)+D_{\mathrm{uz}} \sigma_{\mathrm{n}} \exp \left(\sigma_{\mathrm{n}} b_{1}\right)\right]}{D_{z}}
$$

where $W_{1}=-\frac{\theta_{\mathrm{um}}}{\theta_{\mathrm{m}}} \frac{\exp \left[\sigma_{\mathrm{n}}\left(b_{1}+b_{2}\right)-\beta_{\mathrm{n}}\left(b_{1}+b_{2}\right)\right]}{\exp \left[\sigma_{\mathrm{n}} b_{1}\right]-\exp \left[\sigma_{\mathrm{n}}\left(b_{1}+b_{2}\right)-\beta_{\mathrm{n}} b_{2}\right]}$ and $W_{2}=\frac{\theta_{\mathrm{um}} / \theta_{\mathrm{m}}}{\exp \left[\sigma_{\mathrm{n}} b_{1}\right]-\exp \left[\sigma_{\mathrm{n}}\left(b_{1}+b_{2}\right)-\beta_{\mathrm{n}} b_{2}\right]}$

\subsection{Solutions in real-time domain}

Eqs. (8) - (9) are analytical solutions of solute transport in the aquifer-aquitard system in

Laplace domain. As the mathematical expression of $\omega_{\mathrm{n}}$ included in these equations is complex,

256 the analytical solutions could not be derived easily in the real-time domain from the Laplace domain. Alternatively, the numerical inverse Laplace transform method will be adopted to do so.

258 There are several numerical inverse Laplace transform methods available, such as the Stehfest

259 method (Stehfest and Harald, 1970a; Stehfest and Harald, 1970b), the Schapery method 
260 (Schapery, 1962), the Fourier series method (Dubner and Abate, 1968), and so on. The Stehfest

261 method was demonstrated to perform well in solving the problems related to solute transport

262 (Wang et al., 2020a; Wang et al., 2020b), and will be employed to conduct the inverse Laplace

263 transform on Eqs. (8) - (9) in this study.

264

265

266

267

268

269

270

271

272

273

274

275

276

277

278

279

280 281

\section{Comparison of the new analytical model with numerical modeling}

In this study, the new analytical model is derived by the Laplace transform method and the finite-cosine Fourier transform method. However, the solutions are in Laplace domain, and it needs to conduct numerical inverse Laplace transform to obtain the real-time domain solutions.

To test the new analytical model of this study, a high-resolution finite-difference solution will be employed. The details for discretization could be seen in Appendix B. Eqs. (B5a) - (B5d) are ordinary differential equations, and they could be solved by stiff integrator ODE $15 \mathrm{~s}$ in MATLAB (Shampine and Reichelt, 1997).

Figures $2 \mathrm{a}$ and $2 \mathrm{~b}$ show the comparison between numerical modeling and analytical model.

The parameters used in this case are: $v_{x}=0.5486 \mathrm{~m} \cdot \mathrm{h}^{-1} ; v_{z}=0.0069 \mathrm{~m} \cdot \mathrm{h}^{-1} ; \alpha_{x}=0.5 \mathrm{~m}$;

$\alpha_{z}=\alpha_{\mathrm{uz}}=\alpha_{\mathrm{ux}}=0.1 \mathrm{~m} ; D_{0}=D_{\mathrm{u} 0}=10^{-7} \mathrm{~m}^{2} \cdot \mathrm{h}^{-1} ; R_{\mathrm{m}}=R_{\mathrm{im}}=R_{\mathrm{um}}=R_{\mathrm{uim}}=1 ; \theta_{\mathrm{m}}=0.37 ;$

$\theta_{\mathrm{im}}=0.01 ; \theta_{\mathrm{um}}=0.52 ; \theta_{\mathrm{uim}}=0.01 ; \varepsilon=\varepsilon_{\mathrm{u}}=0.0001 \mathrm{~h}^{-1} ; \lambda_{\mathrm{m}}=\lambda_{\mathrm{im}}=\lambda_{\mathrm{um}}=\lambda_{\mathrm{uim}}=$ $10^{-6} \mathrm{~h}^{-1} ; Q_{\text {in }}=0.0049 \mathrm{~m}^{3} \cdot \mathrm{h}^{-1} ; b_{1}=0.24 \mathrm{~m} ; b_{2}=0.29 \mathrm{~m} ; w_{\text {in }}=w_{\text {out }}=0.1 \mathrm{~m} ; h_{\text {in }}=$ $h_{\text {out }}=0.745 \mathrm{~m} ; L_{\text {in }}=L_{\text {out }}=0.10 \mathrm{~m} ; L_{a}=0.70 \mathrm{~m} ; V_{\text {in }}=V_{\text {out }}=0.00745 \mathrm{~m}^{3}$. The values of these parameters are from the experiment of Li et al. (2021). Figures $2 \mathrm{a}$ and $2 \mathrm{~b}$ indicate that the analytical model agrees very well with the numerical solution, demonstrating that the Stehfest method performs well in conducting the inverse Laplace transform on Eqs. (8) - (9) of this study.

Figure 2 


\section{Applications}

To test the performance of new model, the observation data of solute transport in a 2D experiment by Li et al. (2021) will be employed. In the aquifer-aquitard system, the aquifer dimension is $0.70 \mathrm{~m}$ in length, $0.10 \mathrm{~m}$ in width and $0.24 \mathrm{~m}$ in thickness, and the aquitard dimension is $0.70 \mathrm{~m}$ in length, $0.10 \mathrm{~m}$ in width and $0.29 \mathrm{~m}$ in thickness. The experimental setup is as shown in Figure 1 of $\mathrm{Li}$ et al. (2021). The dimensions of the pre-inlet and after-outlet reservoirs are the same and $0.10 \mathrm{~m}$ in length, $0.10 \mathrm{~m}$ in width and $0.745 \mathrm{~m}$ in thickness. The lithologies of the aquifer and aquitard are coarse sand with grain sizes ranging from 0.50 to $0.90 \mathrm{~mm}$ and well sorted clay, respectively. The hydraulic conductivities of aquifer and aquitard 291 are $1.459 \mathrm{~m} \cdot \mathrm{h}^{-1}$ and $0.000129 \mathrm{~m} \cdot \mathrm{h}^{-1}$, respectively. The porosities of aquifer and aquitard are 2920.37 and 0.52 , respectively. The hydraulic heads are $1.486 \mathrm{~m}$ and $1.437 \mathrm{~m}$ in pre-inlet and after293 outlet reservoirs, respectively. They keep constant during the entire experiment. After the flow 294 flied is in the steady state, the tracer is injected into the pre-inlet reservoir. As the top elevation 295 of the aquitard (e.g., $0.53 \mathrm{~m}$ ) is smaller than the hydraulic heads in the reservoirs, the aquifer is 296 confined under the steady-state flow field. Li et al. (2021) employed the Darcy's law to compute

297 the 1D averaged Darcy velocities, and they were $q_{x}=0.203 \mathrm{~m} \cdot \mathrm{h}^{-1}$ and $q_{z}=0.000359 \mathrm{~m}$. $298 \mathrm{~h}^{-1}$, respectively.

299 To interpret the experimental data of solute transport in the aquifer-aquitard system, Li et al.

300 (2021) employed a 2D ADE model as the governing equation, where the hydrodynamic

301 dispersion and advection are 2D in both aquifer and aquitard. As for the source concentration in 302 the pre-inlet reservoir, they employed an exponential function to describe the variation 303

$$
C_{\text {in }}(t)=C_{0}[1-\exp (-\zeta t)]
$$


304 where $\zeta$ is a constant $\left[\mathrm{T}^{-1}\right]$. Since the observation data of the concentration in the pre-inlet

305 reservoir $\left(C_{\mathrm{in}}(t)\right)$ is not available in the experiment of Li et al. (2021) (probably not measured),

306 the values of $\zeta$ could not be estimated directly. By checking the fitness of observed BTCs by

307 the 2D ADE model (Figures 7 and 8 in Li et al. (2021) or Figures 3 and 4 in this study), one may

308 find that it is not very well, especially at the observation points of (55), (13), (33), (14), (15) and

309 (25). The spatial locations of observation points could be seen in Figure 1 of Li et al. (2021). In

310 this study, the 2D ADE model used in Li et al. (2021) is called Li's model. As the lithologies of

311 the aquifer and aquitard are almost homogeneous, we may assume that the 2D ADE model could

312 be used to describe the solute transport in the aquifer-aquitard system. Therefore, such large

313 errors caused by Li's model might originate from the two types of issues. Firstly, Eq. (11) might

314 not accurately describe the source concentration variation in the pre-inlet reservoir. Secondly, the

315 parameters used in the 2D ADE model could not represent the real processes of solute transport.

Figure 3

317 To test the performance of the analytical model of this study, we employ Eqs. (8) - (9) to

318 reinterpret the observation data. The first type of issue resulting in errors by Li's model could be

319 solved using the model of this study. As mentioned in Section 2.2, the values of $C_{\text {in }}(t)$ could be

320 computed if the parameters of injection rate, water volume of the reservoirs, and $C_{0}$ are given.

321 These parameters could be found in Li et al. (2021): $Q_{\text {in }}=0.0049 \mathrm{~m}^{3} \cdot \mathrm{h}^{-1}$, and $V_{\text {in }}=V_{\text {out }}=$

$3220.00745 \mathrm{~m}^{3} . C_{0}$ is included in the relative concentration $\left(C / C_{0}\right)$, as shown in Figures 3 and 4.

323 As for the first type of issue, we estimate the parameters using the trial-and-error method, and

324 they are: $v_{z}=0.0001 \mathrm{~m} \cdot \mathrm{h}^{-1} ; \alpha_{x}=0.025 \mathrm{~m} ; \alpha_{z}=0.015 \mathrm{~m} ; \alpha_{\mathrm{uz}}=\alpha_{\mathrm{ux}}=0.02 \mathrm{~m}$. The other

325 parameters involved in the analytical model are measured in the experiment, and the values are

326 same as ones used in Figure 2. The fitness of observed BTCs by the new analytical model is 
327 shown in Figures 3 and 4. For the sake of comparison, the computed BTCs by Li's model are

328 also included. Results show that the analytical model of this study performs better than Li's

329 model. Table 1 shows the errors between observed and computed BTCs, where the errors are

330 computed by (Moriasi et al., 2007)

$$
\operatorname{RSR}=\frac{\sqrt{\sum_{i=1}^{\mathrm{NN}}\left(Y_{i}^{\text {obs }}-Y_{i}^{\text {est }}\right)^{2}}}{\sqrt{\sum_{i=1}^{\mathrm{NN}\left(Y_{i}^{\text {obs }}-Y^{\text {mean }}\right)^{2}}}}
$$

332 where $Y_{i}^{\text {obs }}$ is the $i^{\text {th }}$ observed value, $Y_{i}^{\text {est }}$ is the $i^{\text {th }}$ estimated value, $Y^{\text {mean }}$ is the mean of 333 the observation data, and $\mathrm{NN}$ is the total number of observations. A smaller RSR means that

334 the model is more accurate. The model is perfect when RSR $=0$. Obviously, the values of RSR 335 are smaller for the model used in this study than Li's model.

\section{Figure 4}

\section{Table 1}

As the advection is 2D in the governing of Li et al. (2021), but it is $1 \mathrm{D}$ in this study, Li's model is an extension of the analytical model of this study when $\varepsilon=0$. The parameters

340 estimated in this study are different from ones used in Li's model, which are $v_{z}=0.0069 \mathrm{~m}$.

$341 \mathrm{~h}^{-1} ; \alpha_{x}=0.0045 \mathrm{~m} ; \alpha_{z}=0.004 \mathrm{~m} ; \alpha_{\mathrm{uz}}=\alpha_{\mathrm{ux}}=0$. Probably, one may raise two questions

342 about the performance of the new analytical model. Firstly, in the analytical model of this study,

343 the flow velocity is assumed to be horizontal in the aquifer and vertical in the aquitard. Although

344 such an assumption has been widely used in the analytical models to approximate the 2D

345 velocity, it may cause great errors in interpreting the experimental data. To answer this question,

346 we compare the solutions by Li's model and the analytical model of this study under the special

347 case, where $\varepsilon=0$ and Eq. (11) are used to describe the source concentration instead of Eqs. (6a)

$348-(6 b)$ in the analytical model. " $\varepsilon=0$ " means that the MIM model reduces to the ADE model. 
349 The other parameters used in these two models are the same. The results are as shown in Figures

$3505 \mathrm{a}$ and $5 \mathrm{~b}$, the difference between them is not obvious exception when $t<0.5 \mathrm{~h}$. Therefore, one

351 may conclude that the assumption related the advection used in the analytical model is robust.

352 The second question is that the larger errors caused by Li's model might be due to the

353 second type of issue mentioned above, not the first type of issue. In another word, the errors

354 caused by Eq. (11) might be negligible, and the fitness of observed BTCs by Li's model could be 355 improved by adjusting the parameter values. To test whether Eq. (11) could be used to describe

356 the source concentration properly, we compare the models by Li's model and the analytical

357 model of this study when $\varepsilon=0$. The source concentration is described by Eqs. (6a) - (6b) in the

358 analytical model of this study, and by Eq. (11) in Li's model. The parameters used in these two

359 models are the same, except $\zeta=0.000575 \mathrm{~h}^{-1}$ used in Li's model and $C_{\mathrm{in}}(t)$ computed by

360 Eqs. (6a) - (6b). Figures 5a and 5b show the differences between two models are obvious.

361 Therefore, the errors caused by Eq. (11) are not negligible, and the performance of the new

362 analytical model is better.

\section{Figure 5}

\section{Results and Discussions}

\subsection{Effect of $V_{\text {in }}$ on solute transport in aquifer-aquitard system}

In this study, new models describing the concentration variation in the reservoirs connecting

367 aquifer-aquitard system are proposed and incorporated in the analytical model of solute transport

368 in the aquifer-aquitard system. From Eq. (6), one may find that $V_{\text {in }}$ is a main parameter

369 influencing $C_{\text {in }}(t)$. To test the effect of $V_{\text {in }}$ on solute transport in aquifer-aquitard system, three

370 sets of $V_{\text {in }}$ are employed: $V_{\text {in }}=0,0.005 \mathrm{~m}^{3}$ and $0.01 \mathrm{~m}^{3}$. The other parameters are the same as 
371 ones used in Figure 2. Figures 6 and 7 show the comparison of BTCs and the residence time

372 distributions (RTDs) for different $V_{\text {in }}$ and $z$, respectively.

373 Two interesting observations could be found in Figure 6. Firstly, BTCs decrease with

374 increasing $V_{\mathrm{in}}$. When $V_{\mathrm{in}}=0$, BTC is largest. " $V_{\text {in }}=0$ " implies that the tracer concentration in

375 pre-inlet reservoir is the same as the concentration of the injected tracer during the entire

376 experiment, which is not true but for the purpose of comparison. Such observation could be

377 explained as follows. A larger $V_{\text {in }}$ means that there is a larger volume original water in the pre-

378 inlet reservoir. After the injected tracer mixes with the original water in the reservoir, the tracer

379 concentration becomes smaller. Therefore, a larger $V_{\text {in }}$ makes a smaller tracer concentration in

380 the reservoir. The case of $V_{\text {in }}=0$ means the volume of water the reservoir is zero, and no

381 mixing processes occur between the injected tracer and original water in the pre-inlet reservoir.

382 Secondly, the influence of $V_{\text {in }}$ on BTCs is larger in the aquifer than that in the aquitard. This is

383 because the aquifer has larger permeability resulting in the greater advection and dispersion, and

384 the tracer moves faster in the aquifer.

Figure 6

386 Figure 7 shows the influence of $V_{\text {in }}$ on RTDs. RTD is a unimodal and asymmetric curve.

387 One may find that such influence is obvious, and a larger $V_{\text {in }}$ makes RTD flatter. The peak

388 values of RTDs decrease with increasing $V_{\text {in }}$, while the time corresponding to the peak value

389 increases with increasing $V_{\text {in }}$.

Figure 7

\section{6.2. Mass flux crossing the aquifer-aquitard interface}

392 As the aquitard has low permeability, the flow velocity is generally small. Then, many

393 previous studies ignored the effects of dispersion and advection during solute transport in the 
394 aquitard (Sudicky and Frind, 1982; Sudicky et al., 1985; Tang et al., 1981). As a result, the mass

395 flux (MF) crossing the aquifer-aquitard interface is underestimated. However, numerous recent

396 studies demonstrated that MF of the chemicals from the aquitard might be an important factor

397 influencing the water quality in the adjacent aquifer, since the clayey aquitard is enriched in

398 heavy metal elements (Guerrero et al., 1993; Hendry et al., 2004; Lin and Puls, 2000; Mazurek et

399 al., 2011).

400 MF is an important variable to show how much tracer enters or releases from the aquitard,

401 and it is affected by the diffusion, dispersion, and advection. Figure 8 shows the variation of MF

402 with distance at different times. MF is computed by Eq. (3). The parameters used in this figure

403 are same as ones used in Figure 3. Two interesting observations could be found. Firstly, MF

404 decreases with distance along the $x$ axis. This is because the origin of the coordinate system is

405 located at the inlet boundary, where the concentration is maximum. Secondly, MF increases with

406 the time. This observation could be explained by the boundary conditions of the aquifer-aquitard

407 interface. As the diffusion, dispersion, and flow velocity are constant in the aquitard, MF is

408 controlled by the concentration at the aquifer-aquitard interface, which increases with time.

Figure 8

410 Figure 9 shows the contributions of the diffusion, dispersion, and advection in aquitard on

$411 \mathrm{MF}$. The legend of $\mathrm{MF}_{\mathrm{ADD}}$ means total mass flux of tracer crossing the aquifer-aquitard interface,

412 which is calculated by considering diffusion, dispersion, and advection. The legend of $\mathrm{MF}_{\mathrm{Adv}}$,

$413 \mathrm{MF}_{\text {Dis }}$ and $\mathrm{MF}_{\text {Dif }}$ respectively represent the calculation of $\mathrm{MF}$ only considering advection, $\mathrm{MF}$

414 only considering dispersion, and MF only considering diffusion. One may find that the

415 contributions of these three processes from large to small is advection, dispersion, and diffusion.

416 The ratio of $\mathrm{MF}_{\text {Dif }}$ to $\mathrm{MF}_{\mathrm{ADD}}$ is $0.01 \%$ which is almost zero, implying that the effect of diffusion 
417 on MF might be negligible in the short time of interest. The contributions of $\mathrm{MF}_{\mathrm{Adv}}$ and $\mathrm{MF}_{\mathrm{Dis}}$ to

$418 \mathrm{MF}_{\mathrm{ADD}}$ are about $11 \%$ and $89 \%$, respectively. Therefore, the models ignoring the advection and

419 dispersion could greatly underestimate MF crossing the aquifer-aquitard interface.

Figure 9

421

422

\subsection{Global sensitivity analysis}

From the analytical model of Eqs. (8) - (9), one may find that the main parameters affecting BTCs are: $v_{x}, v_{z}, \alpha_{x}, \alpha_{z}, \alpha_{\mathrm{uz}}, \alpha_{\mathrm{ux}}, \theta_{\mathrm{u}}, \theta_{\mathrm{m}}, b_{1}, b_{2}, R_{\mathrm{um}}, R_{\mathrm{m}}, \varepsilon, \varepsilon_{\mathrm{u}}, \lambda, \lambda_{\mathrm{u}}, V_{\mathrm{in}}$ and $V_{\text {out }}$. To test how these parameters affect the solute transport in the aquifer-aquitard system, the global sensitivity analysis is conducted. To date, there are many global sensitivity analysis methods available, such as the Morris screening method (Morris, 1991), regression analysis (TiscarenoLopez et al., 1993), variance-based method (Saltelli et al., 2008), meta-modeling method (Sathyanarayanamurthy and Chinnam, 2009), and so on. As the Morris screening method has lower computation, it will be used in this study (Morris, 1991)

$$
\begin{aligned}
& \sigma_{i}=\sqrt{\frac{1}{j} \sum_{l=1}^{j}\left(E_{i}^{l}-\mu_{i}\right)^{2}}, i=1,2, \ldots, I, \\
& \mu_{i}^{*}=\sum_{l=1}^{j}\left(\left|E_{i}^{l}\right| / j\right), i=1,2, \ldots, I, \\
& \mu_{i}=\sum_{l=1}^{j}\left(E_{i}^{l} / j\right), i=1,2, \ldots, I,
\end{aligned}
$$

where $\sigma_{i}$ and $\mu_{i}^{*}$ are the standard deviation and absolute mean of sample points, respectively; a larger $\mu_{i}^{*}$ means greater sensitivity of the $i^{\text {th }}$ parameter on the output results, while the larger $\sigma_{i}$ implies higher interaction effects and/or non-linear effects of the $i^{\text {th }}$ parameter than others; $j$ is the total number of the sample points and $j=30$ in this study; $I$ is the number of the total number of parameters and $I=18$ in this study; $E_{i}^{l}=\frac{C_{\mathrm{m}}\left(p_{1}, p_{2}, \ldots, p_{i}+l \Delta, \ldots, p_{n}\right)-C_{\mathrm{m}}\left(p_{1}, p_{2}, \ldots, p_{i}, \ldots, p_{n}\right)}{l \Delta}$ where $p_{i}$ is a value of the $i^{\text {th }}$ input parameter in the range of $\left(p_{i, 0}, p_{i, l i m}\right) ; p_{i, 0}$ and $p_{i, \text { lim }}$ are 
439 the smallest and the largest values of $p_{i}$, respectively, as shown in Table $2 ; \Delta$ represents a small

$440 \quad$ increment and $\Delta=1 /(j-1)$.

$441 \quad$ Figures $10 \mathrm{a}$ and $10 \mathrm{~b}$ show that the variation of $\mu_{i}^{*}$ and $\sigma_{i}$ with time in the aquifer (at

$442 z=0.16 \mathrm{~m}$ and $x=0.10 \mathrm{~m})$, respectively. Figure 10a indicates that the values of $\mu_{i}^{*}$ from

443 large to small is $V_{\mathrm{in}}, \theta_{\mathrm{m}}, v_{x}, \alpha_{x}, \alpha_{\mathrm{uz}}, \alpha_{\mathrm{z}}, \theta_{\mathrm{u}}, \alpha_{\mathrm{ux}}, v_{z}, b_{1}, R_{\mathrm{m}}, \varepsilon, \varepsilon_{\mathrm{u}}, V_{\mathrm{out}}, b_{2}, R_{\mathrm{um}}, \lambda_{\mathrm{m}}$

444 and $\lambda_{\mathrm{um}}$. It implies the concentration is more sensitive to the change in $V_{\mathrm{in}}, \theta_{\mathrm{m}}$ and $v_{z}$ than

445 the other parameters. Figure $10 \mathrm{~b}$ shows that the order of $\sigma_{i}$ from large to small is $V_{\mathrm{in}}, \theta_{\mathrm{m}}, v_{x}$, $446 \alpha_{x}, \alpha_{\mathrm{ux}}, \alpha_{\mathrm{ux}}, \theta_{\mathrm{u}}, \alpha_{z}, v_{z}, b_{1}, R_{\mathrm{m}}, b_{2}, \varepsilon_{\mathrm{u}}, \varepsilon, R_{\mathrm{um}}, \lambda_{\mathrm{m}}, \lambda_{\mathrm{um}}$ and $V_{\text {out }}$. It means that $V_{\mathrm{in}}, \theta_{\mathrm{m}}$

447 and $v_{x}$ have the higher interaction effects and/or non-linear effects than others.

448 In summary, the output concentration of solute transport in the aquifer-aquitard system is 449 most sensitive to $V_{\text {in }}$, demonstrating that the variation of the tracer concentration in the pre-inlet 450 reservoir is important for solute transport in an aquifer-aquitard system in the laboratory451 controlled experiment.

Figure 10

Table 2

\section{4}

455

456

457

458

459

460

461

\section{Summary and conclusions}

The laboratory-controlled experiment is an effective technique to investigate the mechanism of solute transport in an aquifer-aquitard system. When injecting tracer (or chemicals) into (or extracting them from) the aquifer or aquitard during experiments, reservoirs are indispensable. As the observation data is generally few during the experiment, mathematical modeling has been widely used to aid understanding the physical and chemical processes of tracer. However, the concentration variation in the reservoirs did not be treated properly in previous analytical models, resulting in poor performance in interpreting experimental data. In this study, we develop the 
462 new mathematical models describing the concentration variation in pre-inlet and after-outlet

463 reservoirs. Such models are incorporated into the mathematical model of solute transport in the

464 aquifer-aquitard system, and a novel analytical model is derived by Laplace transform method

465 and the finite-cosine Fourier transform method under the MIM framework. The new analytical

466 model considers the longitudinal and vertical dispersion, the advection, and the first-order

467 chemical reaction in both aquifer and aquitard. The new analytical model is tested by the finite-

468 difference solution and the experimental data reported by Li et al. (2021). The global sensitivity

469 analysis method of Morris (1991) is conducted to investigate the influences of input parameters

470 on the output concentration of solute transport. The following conclusions could be drawn from

471 this study.

472 (1) When the concentration variation in the reservoirs is not measured during the

473 experiment or the observation data is not available, it could be computed using the parameters of

474 injection rate, water volume of the reservoirs, and the concentration of the injected tracer by the

475 new models of this study.

476 (2) The new analytical model outperforms the previous models in interpreting experimental

477 data.

478 (3) The influence of $V_{\text {in }}$ on BTCs and RTDs is obvious and not negligible. BTCs decreases

479 with increasing $V_{\text {in }}$. The peak values of RTDs decrease with increasing $V_{\text {in }}$, while the time

480 corresponding to the peak value increases with increasing $V_{\text {in }}$.

481 (4) The effect of diffusion on total mass flux of tracer $\left(\mathrm{MF}_{\mathrm{ADD}}\right)$ is about $0.1 \%$, and could be 482 negligible in the short time of interest, while the contributions of $\mathrm{MF}_{\mathrm{Adv}}$ and $\mathrm{MF}_{\mathrm{Dis}}$ to $\mathrm{MF}_{\mathrm{ADD}}$ are 483 about $11 \%$ and $89 \%$, respectively. 
(5) The global sensitivity analysis shows the variation of the tracer concentration in the preinlet reservoir is important for solute transport in an aquifer-aquitard system in the laboratorycontrolled experiment.

\section{7}

488

489

490

491

492

\section{4}

495

496

\section{7}

498

499

500

501

502

503

\section{Acknowledgments}

- This research was partially supported by Programs of Natural Science Foundation of China (No.41772252, No. 41972250 and No.41502229); Innovative Research Groups of the National Nature Science Foundation of China (No. 41521001), the Fundamental Research Funds for the Central Universities, and China University of Geosciences (Wuhan) (No. CUGGC07); the 111 Program (State Administration of Foreign Experts Affairs \& the Ministry of Education of China, No. B18049).

\section{Declaration of interests}

- The authors declare that they have no known competing financial interests or personal relationships that could have appeared to influence the work reported in this paper.

\section{Appendix A. Derivation of analytical solution}

Conducting Laplace transform to Eqs. (1a) - (1b) and Eqs. (6) - (7), one has

$$
\begin{aligned}
& D_{x} \frac{\partial^{2} \bar{C}_{\mathrm{m}}}{\partial x^{2}}+D_{z} \frac{\partial^{2} \bar{C}_{\mathrm{m}}}{\partial z^{2}}-v_{x} \frac{\partial \bar{C}_{\mathrm{m}}}{\partial x}-E_{1} \bar{C}_{\mathrm{m}}=0=0,0 \leq z \leq b_{1}, 0 \leq x \leq L_{\mathrm{a}}, \\
& \bar{C}_{\mathrm{im}}=\frac{\varepsilon / \theta_{\mathrm{im}}}{\varepsilon / \theta_{\mathrm{im}}+\lambda_{\mathrm{im}}+R_{\mathrm{im}} s} \bar{C}_{\mathrm{m}}, 0 \leq z \leq b_{1}, 0 \leq x \leq L_{\mathrm{a}}, \\
& {\left.\left[\bar{C}_{\mathrm{m}}(x, z, s)-\alpha_{x} \frac{\partial \bar{C}_{\mathrm{m}}(x, z, s)}{\partial x}\right]\right|_{x=0}=g(s), 0 \leq z \leq b_{1},} \\
& \left.\frac{d \bar{C}_{\mathrm{m}}(x, z, s)}{d x}\right|_{x=L_{a}}=\left.\delta s \bar{C}_{\mathrm{out}}(x, z, s)\right|_{x=L_{a}}, 0 \leq z \leq b_{1},
\end{aligned}
$$

where $E_{1}=\lambda_{\mathrm{m}}+R_{\mathrm{m}} s+\varepsilon / \theta_{\mathrm{m}}-\frac{\varepsilon^{2} / \theta_{\mathrm{m}} \theta_{\mathrm{im}}}{\varepsilon / \theta_{\mathrm{im}}+\lambda_{\mathrm{im}}+R_{\mathrm{im}} s} ; g(s)=\frac{1}{s\left(s V_{\mathrm{in}} / Q_{\mathrm{in}}+1\right)} ; \delta=\frac{V_{\text {out }}}{w_{\text {out }} h_{\mathrm{out}} D_{x}}$. 
Assuming the solution of Eq. (A1) is

$F=\sum_{\mathrm{n}=0}^{\infty} \bar{C}_{\mathrm{m}} \cos \left(\omega_{\mathrm{n}} z\right)$,

Substituting Eq. (A5) into Eq. (A1), one has

where $\omega_{\mathrm{n}}$ is the frequency terms used in the Fourier transform.

511 where $\alpha_{\mathrm{n}}=\frac{v_{x}-\sqrt{v_{x}^{2}+4 D_{x}\left(E_{1}+D_{z} \omega_{\mathrm{n}}^{2}\right)}}{2 D_{x}}$ and $\delta_{\mathrm{n}}=\frac{v_{x}+\sqrt{v_{x}^{2}+4 D_{x}\left(E_{1}+D_{z} \omega_{\mathrm{n}}^{2}\right)}}{2 D_{x}}$.

$$
\bar{C}_{\mathrm{m}}=\sum_{\mathrm{n}=0}^{\infty}\left[\mathrm{N}_{\mathrm{n}} \exp \left(\alpha_{\mathrm{n}} x\right)+\mathrm{D}_{\mathrm{n}} \exp \left(\delta_{\mathrm{n}} x\right)\right] \cos \left(\omega_{\mathrm{n}} z\right)
$$

514 According to the boundary conditions of Eqs. (A3) - (A4), the coef
515 could be obtained, yields $\mathrm{N}_{\mathrm{n}}=\frac{g(s) \frac{4 \sin \left(b_{1} \omega_{\mathrm{n}}\right)}{2 b_{1} \omega_{\mathrm{n}}+\sin \left(2 b_{1} \omega_{\mathrm{n}}\right)}}{\left(1-\alpha_{\mathrm{n}}\right)-\frac{\left(1-\delta_{\mathrm{n}}\right)\left(\alpha_{\mathrm{n}}-\delta s\right) \exp \left(\alpha_{\mathrm{n}} L_{\mathrm{a}}-\delta_{\mathrm{n}} L_{\mathrm{a}}\right)}{\delta_{\mathrm{n}}-\delta s}}$ and

$\mathrm{D}_{\mathrm{n}}=-\frac{\left(\alpha_{\mathrm{n}}-\delta s\right) \exp \left(\alpha_{\mathrm{n}} L_{\mathrm{a}}-\delta_{\mathrm{n}} L_{\mathrm{a}}\right)}{\delta_{\mathrm{n}}-\delta s} \mathrm{~N}_{\mathrm{n}}$.

Conducting Laplace transform to Eqs. (1c) - (1d), Eq. (3) and Eq. (4b), yields

$$
D_{u z} \frac{\partial^{2} \bar{C}_{\mathrm{um}}}{\partial z^{2}}+D_{u x} \frac{\partial^{2} \bar{C}_{\mathrm{um}}}{\partial x^{2}}-v_{z} \frac{\partial \bar{C}_{\mathrm{um}}}{\partial z}-E_{2} \bar{C}_{\mathrm{um}}=0, b_{1} \leq z<b_{1}+b_{2}, 0 \leq x \leq L_{\mathrm{a}},
$$

$$
\bar{C}_{\mathrm{uim}}=\frac{\varepsilon_{\mathrm{u}} / \theta_{\mathrm{uim}}}{\varepsilon_{\mathrm{u}} / \theta_{\mathrm{uim}}+\lambda_{\mathrm{uim}}+R_{\mathrm{uim}} s} \bar{C}_{\mathrm{um}}, b_{1} \leq z<b_{1}+b_{2}, 0 \leq x \leq L_{\mathrm{a}},
$$

$$
\left.\bar{C}_{\mathrm{um}}(x, z, s)\right|_{z=b_{1}+b_{2}}=0,0 \leq x \leq L_{\mathrm{a}}
$$

$$
\left.\bar{C}_{\mathrm{um}}(x, z, s)\right|_{z=b_{1}}=\left.\bar{C}_{\mathrm{m}}(x, z, s)\right|_{z=b_{1}}, 0 \leq x \leq L_{a}
$$

$$
\left.\theta_{\mathrm{um}}\left[v_{z} \bar{C}_{\mathrm{um}}(x, z, s)-D_{\mathrm{uz}} \frac{\partial \bar{C}_{\mathrm{um}}(x, z, s)}{\partial z}\right]\right|_{z=b_{1}}=-\left.\left[\theta_{\mathrm{m}} D_{z} \frac{\partial \bar{C}_{\mathrm{m}}(x, z, s)}{\partial z}\right]\right|_{z=b_{1}}, 0 \leq x \leq L_{a},(\mathrm{~A}
$$

where $E_{2}=\lambda_{\mathrm{um}}+s R_{\mathrm{um}}+\varepsilon_{\mathrm{u}} / \theta_{\mathrm{um}}-\frac{\varepsilon_{\mathrm{u}}^{2} / \theta_{\mathrm{um}} \theta_{\mathrm{uim}}}{\varepsilon_{\mathrm{u}} \theta_{\mathrm{uim}}+\lambda_{\mathrm{uim}}+R_{\mathrm{uim}} s}$. 
Assuming (Rezaei et al., 2016)

$$
\bar{C}_{\mathrm{um}}=\sum_{\mathrm{n}=0}^{\infty}\left[\mathrm{N}_{\mathrm{n}} \exp \left(\alpha_{\mathrm{n}} x\right)+\mathrm{D}_{\mathrm{n}} \exp \left(\delta_{\mathrm{n}} x\right)\right] \times F_{1},
$$

where $F_{1}$ depends on the $z$ coordinate only. Substituting Eq. (A14) into Eq. (A9) yields

$$
D_{\mathrm{uz}} \frac{\partial^{2} F_{1}}{\partial z^{2}}-v_{z} \frac{\partial F_{1}}{\partial z}-\left(E_{2}+D_{\mathrm{ux}} \alpha_{\mathrm{n}}^{2}\right) F_{1}=0, b_{1} \leq z<b_{1}+b_{2}, 0 \leq x \leq L_{\mathrm{a}},
$$

528

529

530

$$
x_{i}=\frac{x_{i+1 / 2}-x_{i-1 / 2}}{2}, i=1,2, \ldots, N \text {, }
$$

where $A_{n}$ and $B_{n}$ are constant, $\beta_{\mathrm{n}}=\frac{v_{z}-\sqrt{v_{z}^{2}+4 D_{\mathrm{uz}}\left(E_{2}+D_{\mathrm{ux}} \alpha_{\mathrm{n}}^{2}\right)}}{2 D_{\mathrm{uz}}}$ and $\sigma_{\mathrm{n}}=\frac{v_{\mathrm{z}}+\sqrt{v_{\mathrm{z}}^{2}+4 D_{\mathrm{uz}}\left(E_{2}+D_{\mathrm{ux}} \alpha_{\mathrm{n}}^{2}\right)}}{2 D_{\mathrm{uz}}}$. The general solution of Eq. (A9) is

$$
\bar{C}_{\mathrm{um}}=\sum_{\mathrm{n}=0}^{\infty}\left[\mathrm{A}_{\mathrm{n}} \exp \left(\beta_{\mathrm{n}} z\right)+\mathrm{B}_{\mathrm{n}} \exp \left(\sigma_{\mathrm{n}} z\right)\right] \times\left[\mathrm{N}_{\mathrm{n}} \exp \left(\alpha_{\mathrm{n}} x\right)+\mathrm{D}_{\mathrm{n}} \exp \left(\delta_{\mathrm{n}} x\right)\right]
$$

According to the boundary conditions of Eqs. (A11) - (A12), the coefficients of $A_{n}$ and $B_{n}$ could be obtained, yields

$$
\mathrm{A}_{\mathrm{n}}=-\frac{\cos \left(\omega_{\mathrm{n}} b_{1}\right) \exp \left[\sigma_{\mathrm{n}}\left(b_{1}+b_{2}\right)-\beta_{\mathrm{n}}\left(b_{1}+b_{2}\right)\right]}{\exp \left[\sigma_{\mathrm{n}} b_{1}\right]-\exp \left[\sigma_{\mathrm{n}}\left(b_{1}+b_{2}\right)-\beta_{\mathrm{n}} b_{2}\right]} \text { and } \mathrm{B}_{\mathrm{n}}=\frac{\cos \left(\omega_{\mathrm{n}} b_{1}\right)}{\exp \left[\sigma_{\mathrm{n}} b_{1}\right]-\exp \left[\sigma_{\mathrm{n}}\left(b_{1}+b_{2}\right)-\beta_{\mathrm{n}} b_{2}\right]}
$$

According to Eq. (A13), one has

$$
\omega_{\mathrm{n}} \tan \left(\omega_{\mathrm{n}} b_{1}\right)=\frac{W_{1}\left[v_{z} \exp \left(\beta_{\mathrm{n}} b_{1}\right)-D_{\mathrm{uz}} \beta_{\mathrm{n}} \exp \left(\beta_{\mathrm{n}} b_{1}\right)\right]}{D_{z}}+\frac{W_{2}\left[v_{z} \exp \left(\sigma_{\mathrm{n}} b_{1}\right)+D_{\mathrm{uz}} \sigma_{\mathrm{n}} \exp \left(\sigma_{\mathrm{n}} b_{1}\right)\right]}{D_{\mathrm{z}}}
$$

where $W_{1}=-\frac{\theta_{\mathrm{um}}}{\theta_{\mathrm{m}}} \frac{\exp \left[\sigma_{\mathrm{n}}\left(b_{1}+b_{2}\right)-\beta_{\mathrm{n}}\left(b_{1}+b_{2}\right)\right]}{\exp \left[\sigma_{\mathrm{n}} b_{1}\right]-\exp \left[\sigma_{\mathrm{n}}\left(b_{1}+b_{2}\right)-\beta_{\mathrm{n}} b_{2}\right]}$ and $W_{2}=\frac{\theta_{\mathrm{um}} / \theta_{\mathrm{m}}}{\exp \left[\sigma_{\mathrm{n}} b_{1}\right]-\exp \left[\sigma_{\mathrm{n}}\left(b_{1}+b_{2}\right)-\beta_{\mathrm{n}} b_{2}\right]}$

\section{Appendix B. The finite-difference solution}

In numerical modeling, the horizontal spatial domain of the aquifer-aquitard system $\left[0, L_{\mathrm{a}}\right]$ 


$$
x_{i+1 / 2}=i \frac{L_{\mathrm{a}}}{N}, i=1,2, \ldots, N \text {. }
$$

546 respectively, and one has

$$
z_{j}=\frac{z_{j+1 / 2}-z_{j-1 / 2}}{2}, j=1,2, \ldots, M_{1},
$$

$$
z_{k}=\frac{z_{k+1 / 2}-z_{k-1 / 2}}{2}, k=1,2, \ldots, M_{2},
$$

549 where $z_{j+1 / 2}$ and $z_{k+1 / 2}$ are

$$
z_{j+1 / 2}=j \frac{b_{1}}{M_{1}}, j=1,2, \ldots, M_{1},
$$

$$
z_{k+1 / 2}=k \frac{b_{2}}{M_{2}}, k=1,2, \ldots, M_{2} .
$$

$$
\frac{\partial C_{\mathrm{m}, i, j}}{\partial t}=
$$

554

$\frac{\frac{D_{\chi} C_{\mathrm{m}, i-1, j}-C_{\mathrm{m}, i, j}}{R_{\mathrm{m}} x_{i}-x_{i-1}}-\frac{D_{x} C_{\mathrm{m}, i, j}-C_{\mathrm{m}, i+1, j}}{R_{\mathrm{m}} x_{i+1}-x_{i}}}{x_{i+1 / 2}-x_{i-1 / 2}}+\frac{\frac{D_{Z} C_{\mathrm{m}, i, j-1}-C_{m, i, j}}{R_{\mathrm{m}} z_{j}-z_{j-1}}-\frac{D_{Z} C_{\mathrm{m}, i, j}-C_{\mathrm{m}, i, j+1}}{R_{\mathrm{m}} z_{j+1}-z_{j}}}{z_{j+1 / 2}-z_{j-1 / 2}}-\frac{v_{x}}{R_{\mathrm{m}}} \frac{{ }_{\mathrm{m}, i+\frac{1}{2}, j}-C_{\mathrm{m}, i-\frac{1}{2}, j}}{x_{i+\frac{1}{2}}-x_{i-\frac{1}{2}}}-\left(\frac{\lambda_{\mathrm{m}}}{R_{\mathrm{m}}}+\right.$

$\left.\frac{\varepsilon}{\theta_{\mathrm{m}} R_{\mathrm{m}}}\right) C_{\mathrm{m}, i, j}+\frac{\varepsilon}{\theta_{\mathrm{m}} R_{\mathrm{m}}} C_{\mathrm{im}, i, j}, i=1,2, \ldots, N, j=1,2, \ldots, M_{1}$, (B5a)

$$
\frac{\partial C_{\mathrm{im}, i, j}}{\partial t}=\frac{\varepsilon}{\theta_{\mathrm{im}} R_{\mathrm{im}}} C_{\mathrm{m}, i, j}-\left(\frac{\varepsilon}{\theta_{\mathrm{im}} R_{\mathrm{im}}}+\frac{\lambda_{\mathrm{im}}}{R_{\mathrm{im}}}\right) C_{\mathrm{im}, i, j}, i=1,2, \ldots, N, j=1,2, \ldots, M_{1},
$$

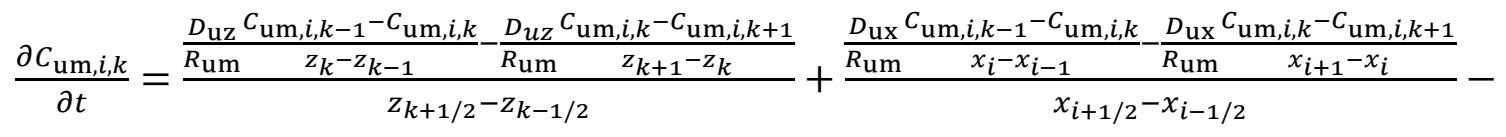

558

$$
\frac{v_{z}}{R_{\mathrm{um}}} \frac{C_{\mathrm{um}, i, k+\frac{1}{2}}{ }^{-} C_{\mathrm{um}, i, k-\frac{1}{2}}}{z_{k+\frac{1}{2}}-Z_{k-\frac{1}{2}}}-\left(\frac{\lambda_{\mathrm{um}}}{R_{\mathrm{um}}}+\frac{\varepsilon_{u}}{\theta_{\mathrm{um}} R_{u m}}\right) C_{u m, i, k}-\frac{\varepsilon_{u}}{\theta_{\mathrm{um}} R_{u m}} C_{\mathrm{uim}, i, k}, i=1,2, \ldots, N, k=
$$

$$
\frac{\partial C_{\mathrm{uim}, i, k}}{\partial t}=\frac{\varepsilon_{\mathrm{u}} C_{\mathrm{um}, i, k}}{\theta_{\mathrm{uim}} R_{\mathrm{uim}}}-\left(\frac{\varepsilon_{\mathrm{u}}}{\theta_{\mathrm{uim}} R_{\mathrm{uim}}}+\frac{\lambda_{\mathrm{uim}}}{R_{\mathrm{uim}}}\right) C_{\mathrm{uim}, i, k}, i=1,2, \ldots, N, k=1,2, \ldots, M_{2},
$$


561 where $C_{\mathrm{m}, i, j}$ and $C_{\mathrm{im}, i, j}$ are the concentrations of mobile zone and immobile zone in the aquifer

562 at node $(i, j)$, respectively; $C_{\mathrm{um}, i, k}$ and $C_{\mathrm{uim}, i, k}$ are the concentrations of mobile zone and

563 immobile zone in the aquitard at node $(i, j)$, respectively.

\section{References}

565 Baeumer, B., Benson, D.A., Meerschaert, M.M., Wheatcraft, S.W., 2001. Subordinated 566 advection - dispersion equation for contaminant transport. Water Resources Research, 37(6):

$567 \quad 1543-1550$.

568 Barbour, S.L., Hendry, M.J., Wassenaar, L.I., 2012. In situ experiment to determine

569 advective-diffusive controls on solute transport in a clay-rich aquitard. Journal of Contaminant $570 \quad$ Hydrology, 131(1-4): 79-88.

571 Chen, C.S., 1985. Analytical and approximate solutions to radial dispersion from an

572 injection well to a geological unit with simultaneous diffusion into adjacent strata. Water

573 Resources Research, 21(8): 1069-1076.

574 Chen, J.-S., Ho, Y.-C., Liang, C.-P., Wang, S.-W., Liu, C.-W., 2018. Analytical model for 575 coupled multispecies advective dispersive transport subject to rate-limited sorption. Hydrology 576 and Earth System Sciences Discussions: 1-45.

577 Chen, K., Zhan, H., 2018. A Green's function method for two-dimensional reactive solute 578 transport in a parallel fracture-matrix system. Journal of Contaminant Hydrology, 213(2018): 1557921.

580 Chen, K., Zhan, H., Yang, Q., 2017. Fractional Models Simulating Non - Fickian Behavior 581 in Four - Stage Single - Well Push - Pull Tests. Water Resources Research, 53(11): 9528-9545. 
Dubner, H., Abate, J., 1968. Numerical Inversion of Laplace Transforms by Relating Them

583

584

585

586

587

to the Finite Fourier Cosine Transform. Journal of the Acm, 15(1): 115-123.

Fujikawa, Y., Fukui, M., 1990. Adsorptive solute transport in fractured rock: analytical solutions for delta-type source conditions. Journal of Contaminant Hydrology, 6(1): 85-102.

Guerrero, A., Cherry, J.A., Rudolph, D.L., 1993. Large - Scale Aquitard Consolidation Near Mexico City. Groundwater, 31(5): 708-718.

Hansen, S.K., Vesselinov, V.V., Reimus, P.W., Lu, Z., 2017. Inferring subsurface heterogeneity from push-drift tracer tests. Water Resources Research, 53(7): 6322-6329.

Hendry, M.J., Kelln, C.J., Wassenaar, L.I., Shaw, J., 2004. Characterizing the hydrogeology of a complex clay-rich aquitard system using detailed vertical profiles of the stable isotopes of water. Journal of Hydrology, 293(1-4): 47-56.

Kookana, R.S., Aylmore, L., Gerritse, R., 1992. Time-dependent sorption of pesticides during transport in soils. Soil science, 154(3): 214-225.

Li, X., Wen, Z., Zhan, H., Wu, F., Zhu, Q., 2021. Laboratory observations for twodimensional solute transport in an aquifer-aquitard system. Environmental Science and Pollution Research, 4(2021): 1-15.

Lin, Z., Puls, R.W., 2000. Adsorption, desorption and oxidation of arsenic affected by clay minerals and aging process. Environmental Geology, 39(7): 753-759.

Liu, C.-T., Yeh, H.-D., Yeh, L.-M., 2013. Modeling contaminant transport in a two-aquifer system with an intervening aquitard. Journal of Hydrology, 499(2013): 200-209.

Mazurek, M. et al., 2011. Natural tracer profiles across argillaceous formations. Applied Geochemistry, 26(7): 1035-1064. 
Confidential manuscript submitted to Environmental Science and Pollution Research

Moriasi, D.N. et al., 2007. Model evaluation guidelines for systematic quantification of

605

606

607

608

609

610

611

612

613

614

615

616

617

618

619

620

621

622

623

624

625

accuracy in watershed simulations. Transactions of the ASABE, 50(3): 885-900.

Morris, M.D., 1991. Factorial Sampling Plans for Preliminary Computational Experiments.

Technometrics, 33(2): 161-174.

Rezaei, A., Zare, M., Zhan, H., 2016. Aquitard Horizontal Dispersion on Reactive Solute

Transport in an Aquifer-Aquitard System. Transport in Porous Media, 113(3): 695-716.

Rezaei, A., Zhan, H., Zare, M., 2013. Impact of thin aquitards on two-dimensional solute transport in an aquifer. Journal of Contaminant Hydrology, 152(2013): 117-136.

Rezanezhad, F. et al., 2017. The Role of Pore Structure on Nitrate Reduction in Peat Soil: A Physical Characterization of Pore Distribution and Solute Transport. Wetlands, 37: 951-960.

Rezanezhad, F. et al., 2016. Structure of peat soils and implications for water storage, flow and solute transport: A review update for geochemists. Chemical Geology, 429: 75-84.

Roubinet, D., de Dreuzy, J.R., Tartakovsky, D.M., 2012. Semi-analytical solutions for solute transport and exchange in fractured porous media. Water Resources Research, 48(1): W01542.

Saltelli, A. et al., 2008. Global sensitivity analysis: the primer. John Wiley \& Sons.

Sathyanarayanamurthy, H., Chinnam, R.B., 2009. Metamodels for variable importance decomposition with applications to probabilistic engineering design. Computers \& Industrial Engineering, 57(3): 996-1007.

Schapery, R.A., 1962. Approximate Methods of Transform Inversion for Viscoelastic Stress Analysis. Proc Fourth USNat Congr Appl Mech, 2(1962):1075.

Shampine, L.F., Reichelt, M.W., 1997. The matlab ode suite. SIAM journal on scientific computing, 18(1): 1-22. 
Confidential manuscript submitted to Environmental Science and Pollution Research

Singh, M.K., Singh, R.K., Pasupuleti, S., 2020. Study of forward-backward solute

627 dispersion profiles in a semi-infinite groundwater system. Hydrological Sciences Journal, 65(8):

$628 \quad 1416-1429$.

629 Starr, R., Gillham, R., Sudicky, E., 1985. Experimental investigation of solute transport in

630 stratified porous media: 2. The reactive case. Water Resources Research, 21(7): 1043-1050.

631 Stehfest, Harald, 1970a. Algorithm 368: Numerical inversion of Laplace transforms [D5].

632 Communications of the Acm, 13(1): 47-49.

633 Stehfest, Harald, 1970b. Remark on algorithm 368: Numerical inversion of Laplace

634 transforms. Communications of the Acm, 13(10): 624.

635 Sudicky, E., Frind, E., 1982. Contaminant transport in fractured porous media: Analytical

636 solutions for a system of parallel fractures. Water Resources Research, 18(6): 1634-1642.

637 Sudicky, E.A., Gillham, R.W., Frind, E.O., 1985. Experimental Investigation of Solute

638 Transport in Stratified Porous Media: 1. The Nonreactive Case. Water Resources Research, 639 21(7): 1043-1050.

640 Tang, D.H., Frind, E.O., Sudicky, E.A., 1981. Contaminant transport in fractured porous 641 media: Analytical solution for a single fracture. Water Resources Research, 17(3): 555-564.

642 Tang, Y., Aral, M.M., 1992. Contaminant transport in layered porous media: 1. General 643 solution. Water Resources Research, 28(5): 1389-1397.

644 Tiscareno-Lopez, M., Lopes, V., Stone, J., Lane, L., 1993. Sensitivity analysis of the WEPP 645 watershed model for rangeland applications I: Hillslope processes. Transactions of the ASAE, 646 36(6): 1659-1672.

647 Van Genuchten, M.T., 1985. Convective-dispersive transport of solutes involved in 648 sequential first-order decay reactions. Computers \& Geosciences, 11(2): 129-147. 
Confidential manuscript submitted to Environmental Science and Pollution Research

Wang, Q., Gu, H., Zhan, H., Shi, W., Zhou, R., 2019. Mixing Effect on Reactive Transport

650 in a Column with Scale Dependent Dispersion. Journal of Hydrology, 582(6): 124494.

651 Wang, Q., Shi, W., Zhan, H., Xiao, X., 2020a. New model of Single-Well Push-Pull thermal

652 test in a Fracture-Matrix system. Journal of Hydrology, 585(2020): 124807.

653 Wang, Q., Wang, J., Zhan, H., Shi, W., 2020b. New model of reactive transport in a single-

654 well push-pull test with aquitard effect and wellbore storage. Hydrology and Earth System

655 Sciences, 24(8): 3983-4000.

656 Wang, Q., Zhan, H., 2013. Radial reactive solute transport in an aquifer-aquitard system.

657 Advances in Water Resources, 61(2013): 51-61.

658 Xao, C., Teng, M., Yao, D., 2020. Arsenic releasing mechanisms during clayey sediments

659 compaction: An experiment study. Journal of Hydrology, 597(2020):125743.

660 Yang, M., Annable, M.D., Jawitz, J.W., 2016. Solute source depletion control of forward

661 and back diffusion through low-permeability zones. Journal of contaminant hydrology,

662 193(2016): 54-62.

663 Yeh, G.T., 2000. Numerical Methods for Advection-Dominant Transport. Computational

664 Subsurface Hydrology, pp. 93-198. Springer, Boston, MA.

665 Zhan, H., Wen, Z., Gao, G., 2009a. An analytical solution of two-dimensional reactive

666 solute transport in an aquifer-aquitard system. Water Resources Research, 45(10): W10501.

667 Zhan, H., Wen, Z., Huang, G., Sun, D., 2009b. Analytical solution of two-dimensional

668 solute transport in an aquifer-aquitard system. Journal of Contaminant Hydrology, 107(3-4):

$669 \quad 162-174$. 
671 advection dispersion and chemical reactions of contaminants in groundwater systems. Rep.,

672 Army Engineer Research and Development Center, Vicksburg, Mississippi; 1999.

673 Zhou, R., Zhan, H., 2018. Reactive solute transport in an asymmetrical fracture-rock matrix

674 system. Advances in Water Resources, 112(2018): 224-234.

675 Zhou, R., Zhan, H., Chen, K., 2017. Reactive solute transport in a filled single fracture-

676 matrix system under unilateral and radial flows. Advances in Water Resources, 104(2017): 183 -

677194.

678 Zhu, Y., Zhan, H., 2018. Quantification of solute penetration in an asymmetric fracture-

679 matrix system. Journal of Hydrology, 563(2018): 586-598. 


\section{Table Caption}

681 Table 1. The values of RSR caused by the models of this study and Li's model.

682 Table 2. Parameter range used in the global sensitivity analysis.

683

684 Figure Caption

685 Figure 1. Schematic diagram of 2D reactive transport in an aquifer-aquitard system in the

686 laboratory-controlled experiment.

687 Figure 2. Comparison between the numerical and analytical solutions. (a) $C_{\mathrm{m}} / C_{0}$ V.S. $t$ at

688 different $z$; (b) $C_{\mathrm{m}} / C_{0}$ V.S. $z$ at different $x$. "ANA" represents the curves produced by the 689 analytical model of this study.

690 Figure 3. Fitness of observed BTCs for different locations in the aquifer. (a) Observation points 691 of (41), (43) and (45); (b) Observation points of (51), (53) and (55).

692 Figure 4. Fitness of observed BTCs for different locations in the aquitard. (a) Observation points 693 of (31), (21) and (11); (b) Observation points of (32), (22) and (12); (c) Observation points of 694 (33), (23) and (13); (d) Observation points of (34), (24) and (14); (e) Observation points of (35), 695 (25) and (1); (f) Observation points of (36), (26) and (16).

696 Figure 5. The comparison of BTCs between the new analytical models and Li's model. (a)

697 Observation points (41), (43) and (45); (b) Observation points (51), (53) and (55).

$698 \quad$ Figure 6. BTCs for different $V_{\text {in }}$ and $z$.

699 Figure 7. RTDs for different $V_{\text {in }}$ and $z$.

700 Figure 8. MF variation crossing the aquifer-aquitard interface along the $x$-direction for 701 different times. 
702 Figure 9. Contributions of the diffusion, dispersion, and advection in aquitard on the aquifer-

703 aquitard interface MF at $t=5.5 \mathrm{~h}$.

704 Figure 10. Sensitivity analysis of the input parameters on the output concentration at $z=0.16 \mathrm{~m}$

705 and $x=0.10 \mathrm{~m}$. (a) Variation in $\mu_{i}^{*}$ with time; (b) Variation in $\sigma_{i}$ with time. 
Figures

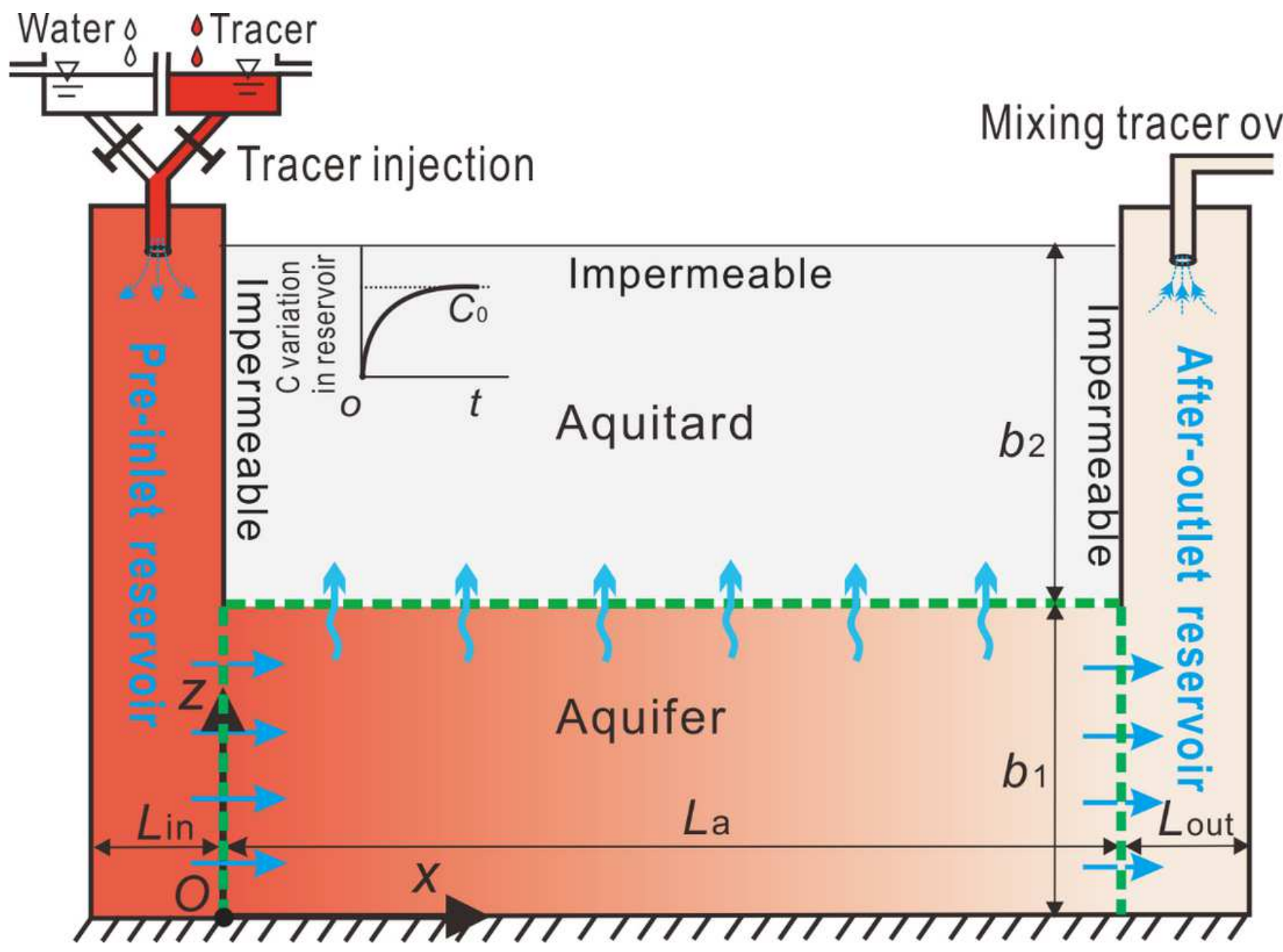

Figure 1

Schematic diagram of 2D reactive transport in an aquifer-aquitard system in the laboratory-controlled experiment. 

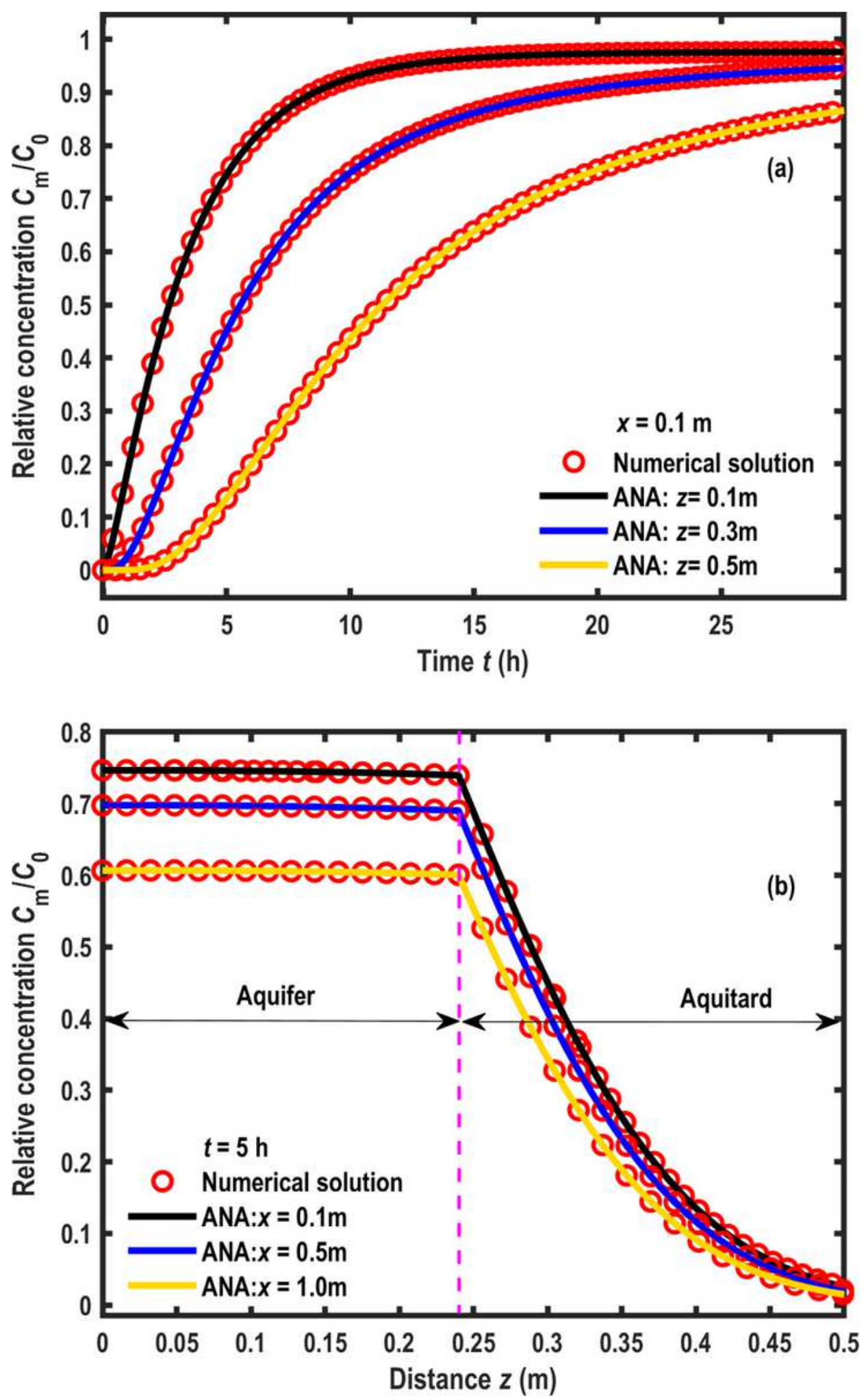

Figure 2

Comparison between the numerical and analytical solutions. (a) V.S. at different; (b) V.S. at different . "ANA" represents the curves produced by the analytical model of this study. 

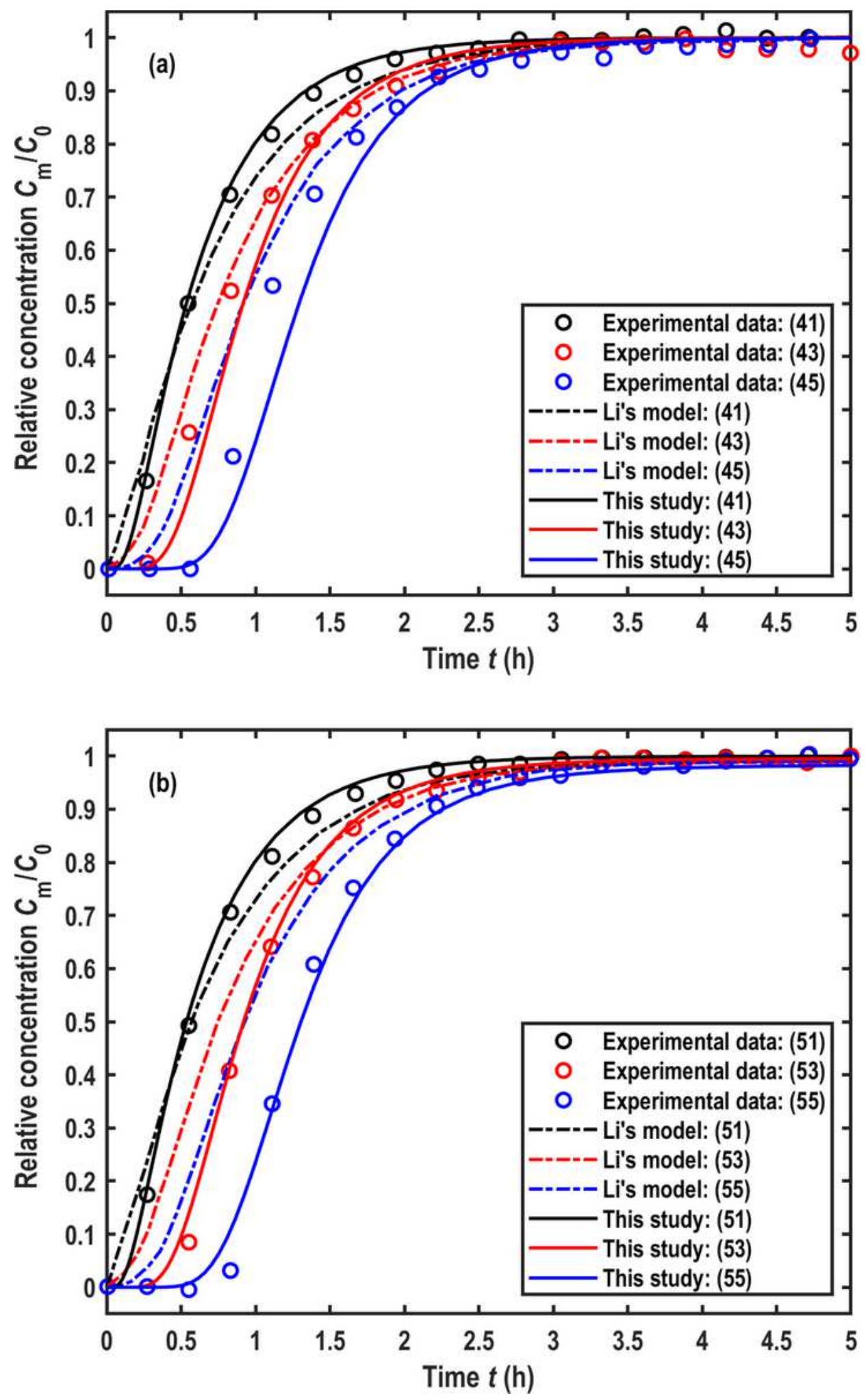

Figure 3

Fitness of observed BTCs for different locations in the aquifer. (a) Observation points of (41), (43) and (45); (b) Observation points of (51), (53) and (55). 

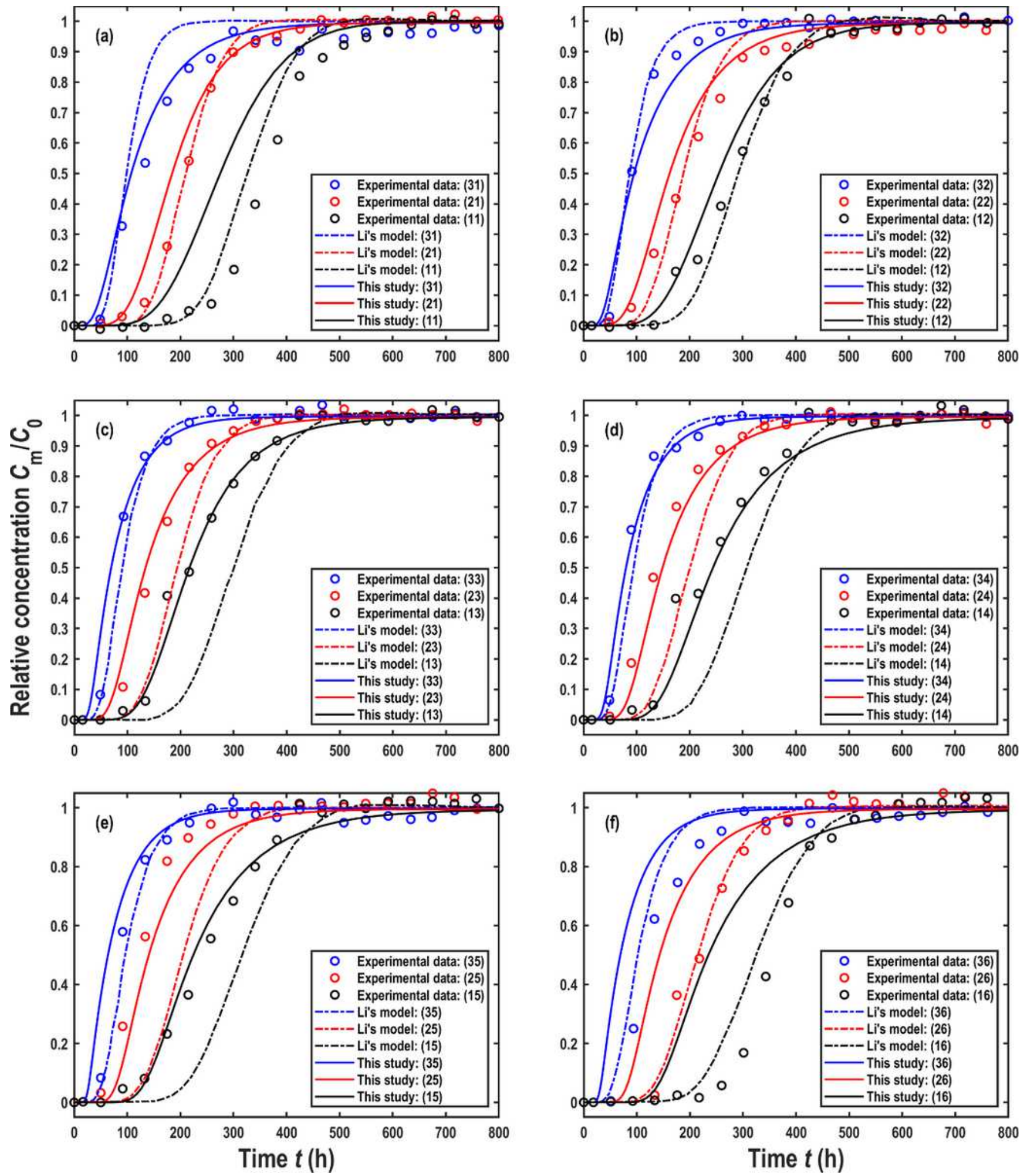

\section{Figure 4}

Fitness of observed BTCs for different locations in the aquitard. (a) Observation points of (31), (21) and (11); (b) Observation points of (32), (22) and (12); (c) Observation points of (33), (23) and (13); (d) Observation points of (34), (24) and (14); (e) Observation points of (35), (25) and (1); (f) Observation points of (36), (26) and (16). 

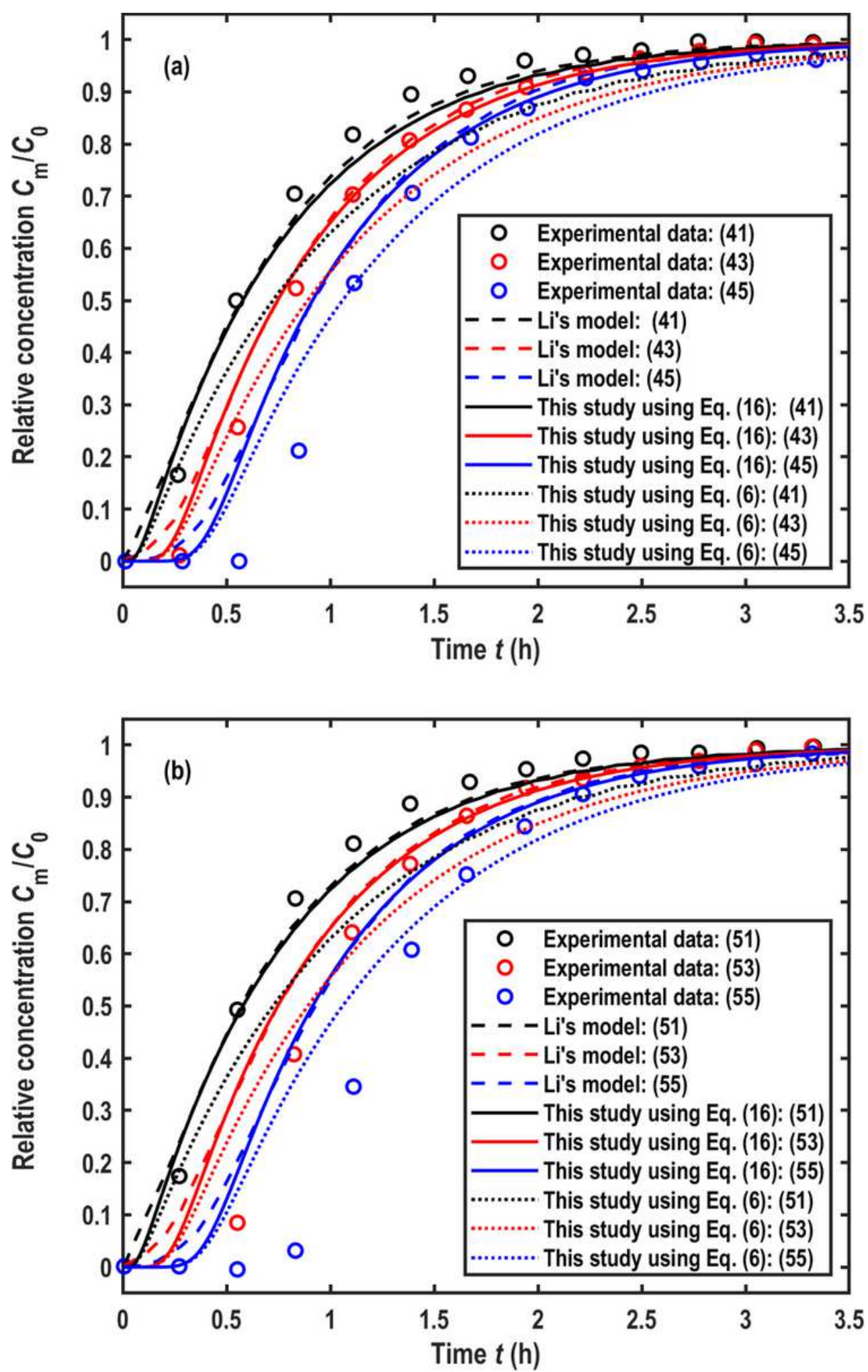

Figure 5

The comparison of BTCs between the new analytical models and Li's model. (a) Observation points (41), (43) and (45); (b) Observation points (51), (53) and (55). 


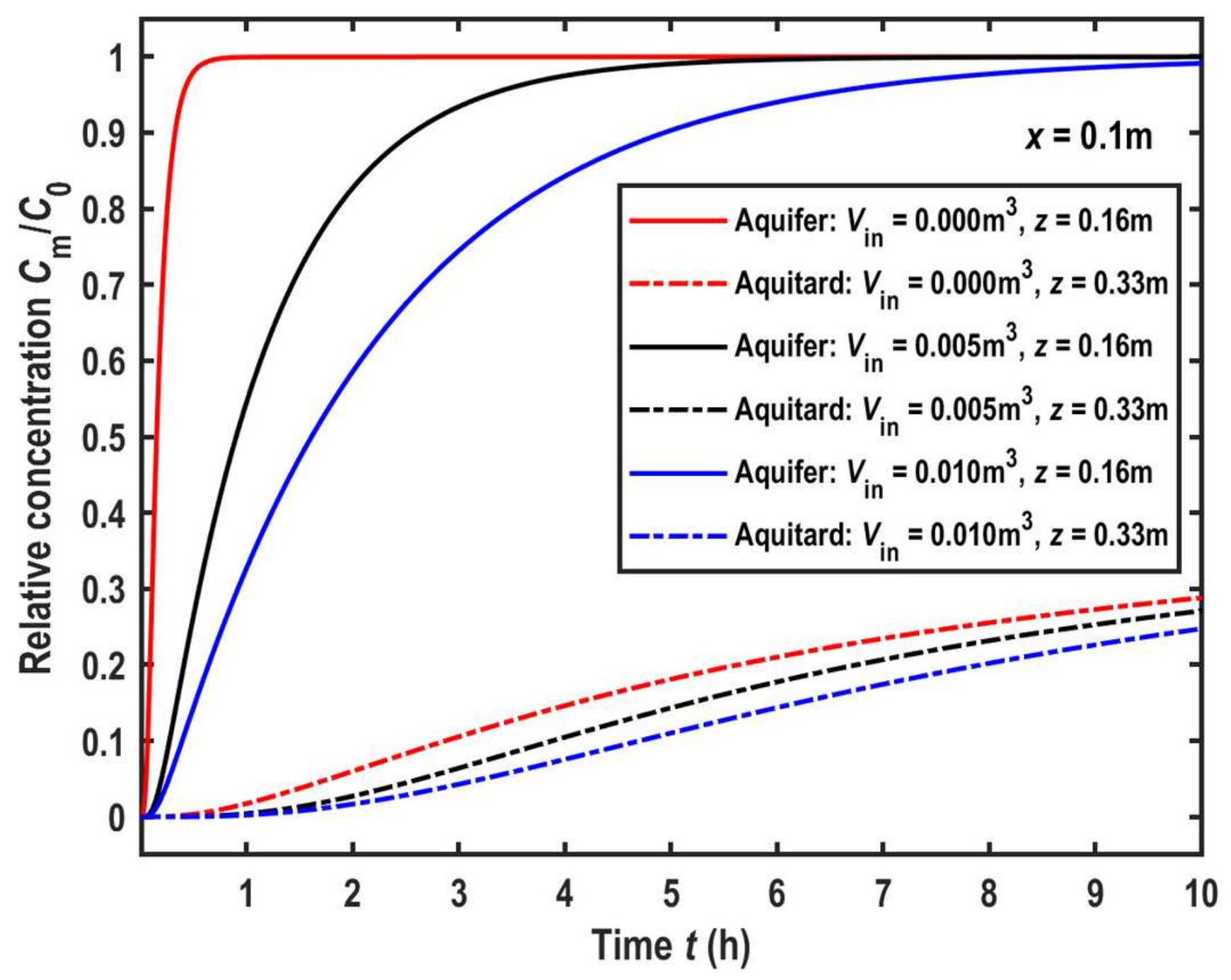

Figure 6

BTCs for different Vin and $z$. 


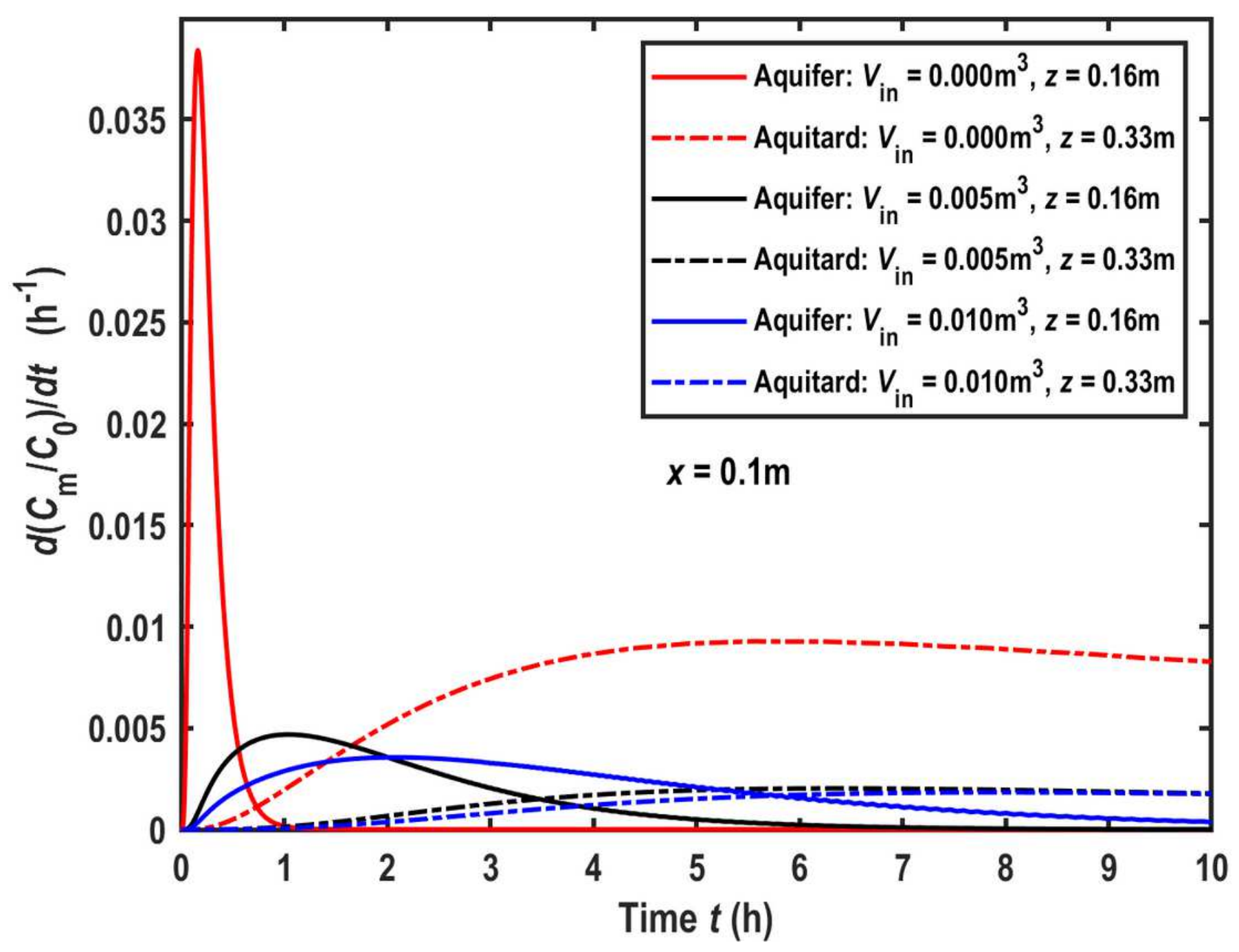

Figure 7

RTDs for different Vin and $z$. 


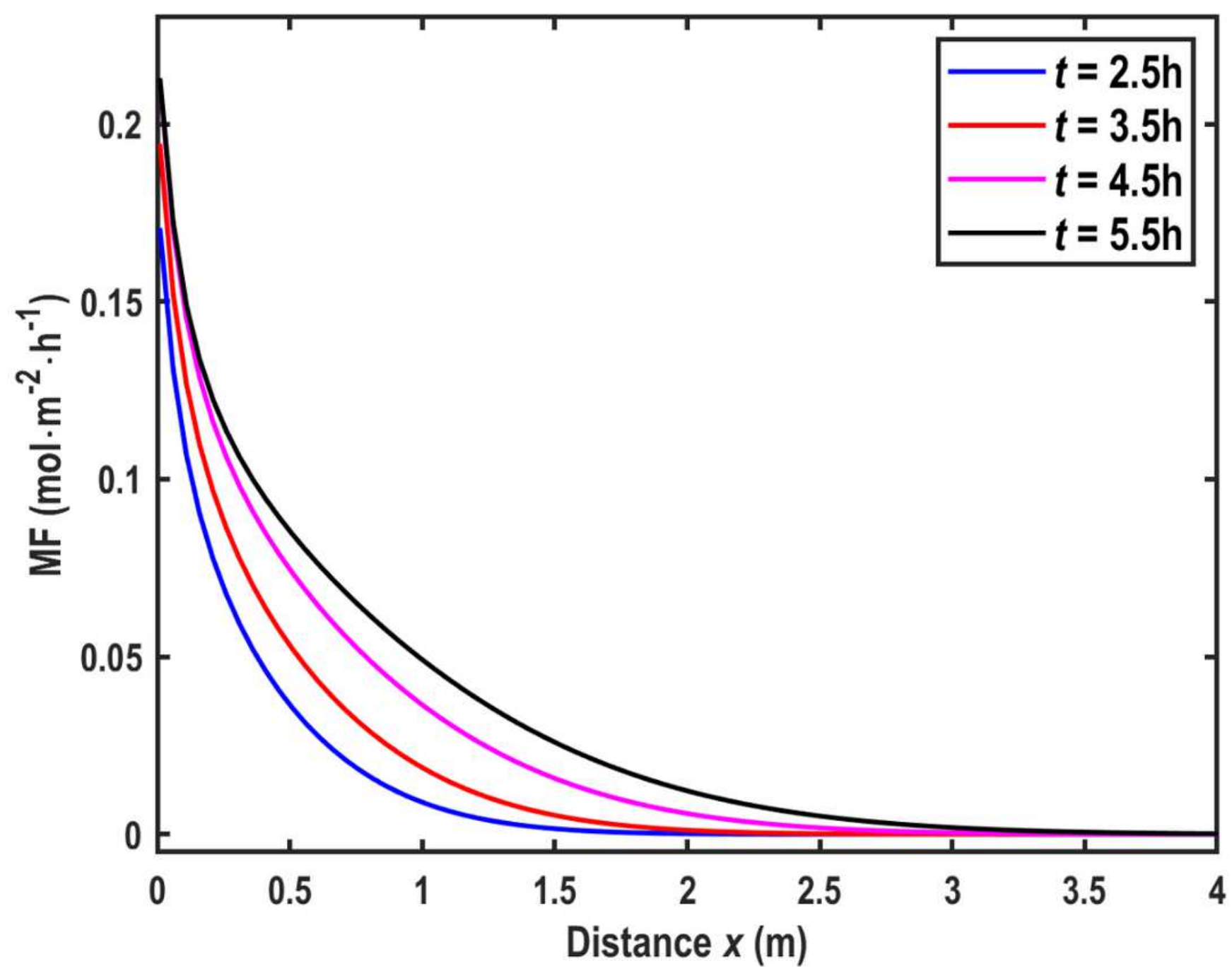

Figure 8

MF variation crossing the aquifer-aquitard interface along the $x$-direction for different times. 


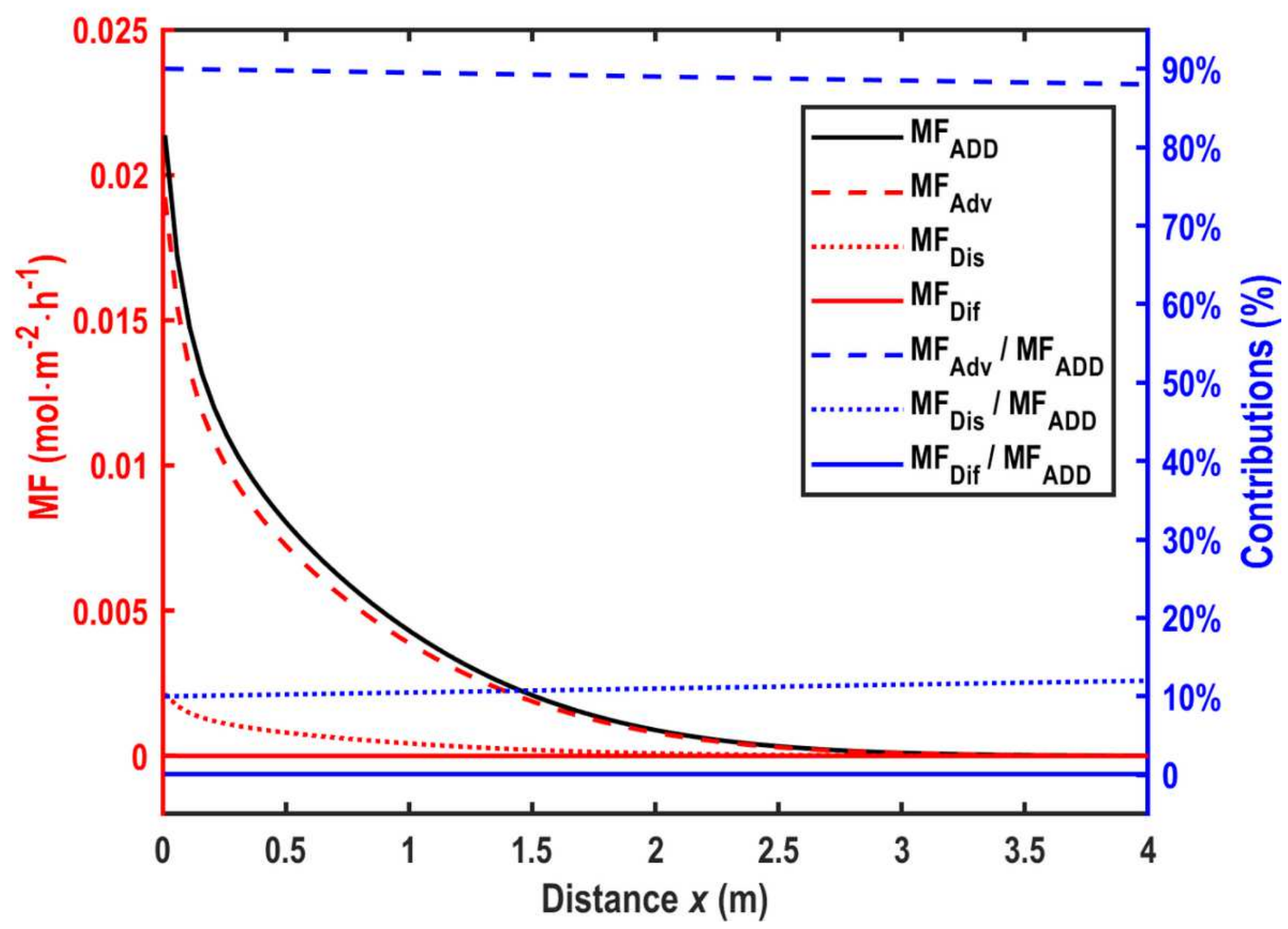

Figure 9

Contributions of the diffusion, dispersion, and advection in aquitard on the aquifer-aquitard interface MF at $t=5.5 \mathrm{~h}$. 

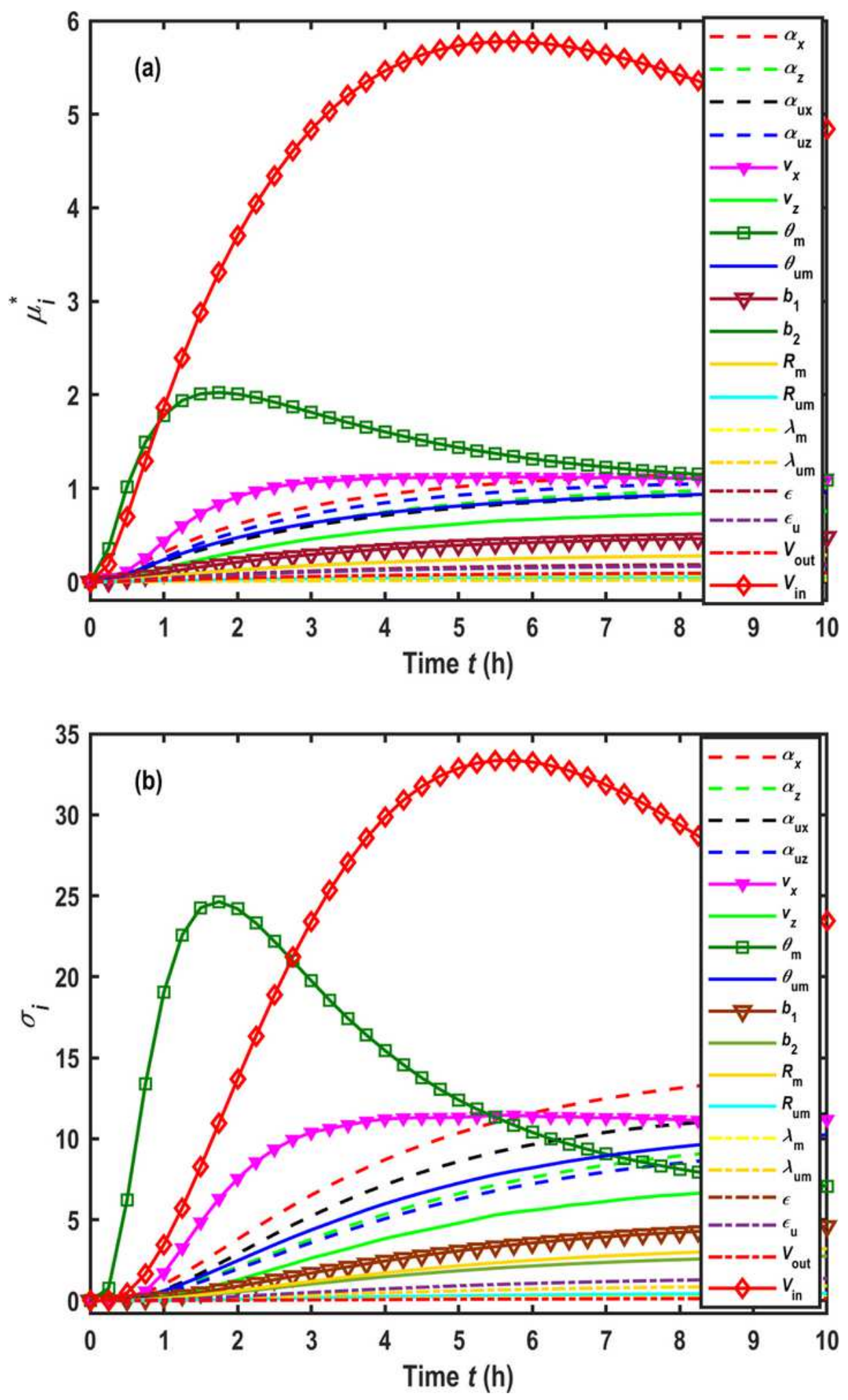

Figure 10

Sensitivity analysis of the input parameters on the output concentration at $z=0.16 \mathrm{~m}$ and $x=0.10 \mathrm{~m}$. (a) Variation in $\mu i^{*}$ with time; (b) Variation in $\sigma i$ with time. 